\title{
Treatment of Acute Lymphoblastic Leukemia from Traditional Chinese Medicine
}

\author{
Ya-Li Hsiao, ${ }^{1}$ Pei-Chun Chang, ${ }^{1}$ Hung-Jin Huang, ${ }^{2}$ \\ Chia-Chen Kuo, ${ }^{1}$ and Calvin Yu-Chian Chen ${ }^{1,2}$ \\ ${ }^{1}$ Department of Biomedical Informatics, Asia University, Taichung 41354, Taiwan \\ ${ }^{2}$ School of Medicine, College of Medicine, China Medical University, Taichung 40402, Taiwan \\ Correspondence should be addressed to Calvin Yu-Chian Chen; ycc929@MIT.edu
}

Received 3 January 2014; Accepted 7 January 2014; Published 22 May 2014

Academic Editor: Fuu-Jen Tsai

Copyright (C) 2014 Ya-Li Hsiao et al. This is an open access article distributed under the Creative Commons Attribution License, which permits unrestricted use, distribution, and reproduction in any medium, provided the original work is properly cited.

Acute lymphoblastic leukemia (ALL) is a cancer that immature white blood cells continuously overproduce in the bone marrow. These cells crowd out normal cells in the bone marrow bringing damage and death. Methotrexate (MTX) is a drug used in the treatment of various cancer and autoimmune diseases. In particular, for the treatment of childhood acute lymphoblastic leukemia, it had significant effect. MTX competitively inhibits dihydrofolate reductase (DHFR), an enzyme that participates in the tetrahydrofolate synthesis so as to inhibit purine synthesis. In addition, its downstream metabolite methotrexate polyglutamates (MTX-PGs) inhibit the thymidylate synthase (TS). Therefore, MTX can inhibit the synthesis of DNA. However, MTX has cytotoxicity and neurotoxin may cause multiple organ injury and is potentially lethal. Thus, the lower toxicity drugs are necessary to be developed. Recently, diseases treatments with Traditional Chinese Medicine (TCM) as complements are getting more and more attention. In this study, we attempted to discover the compounds with drug-like potential for ALL treatment from the components in TCM. We applied virtual screen and QSAR models based on structure-based and ligand-based studies to identify the potential TCM component compounds. Our results show that the TCM compounds adenosine triphosphate, manninotriose, raffinose, and stachyose could have potential to improve the side effects of MTX for ALL treatment.

\section{Introduction}

Dihydrofolate reductase (DHFR) is essential in cellular metabolism and cell growth. It catalyzes the conversion of dihydrofolate into tetrahydrofolate which is a carrier for the methyl group. The methyl group carried by tetrahydrofolate is required for de novo synthesis of varieties of essential metabolites including amino acids, lipids, pyrimidines, and purines. Methotrexate (MTX), a folate antagonist, arrests cell growth by competitively binding to DHFR, thereby, blocking de novo synthesis of nucleotide precursors and inhibiting DNA synthesis [1]. MTX has been found to be useful as an antineoplastic and immunosuppressive agent because it inhibits the proliferation of rapidly dividing malignant [2].

MTX tightly binding on DHFR is one of the most widely used drugs in cancer treatment and is especially effective in the treatment of acute lymphocytic leukemia [3]. In addition, its folate analogue is widely used in the treatment of acute lymphoblastic leukemia (ALL) [4], ovarian cancer [5], osteosarcoma [6], rheumatoid arthritis [7], psoriasis [8], and inflammatory bowel disease [9] and for prevention of graftversus-host disease after transplantation [10].

In the cells, MTX acts by inhibiting two enzymes. First, as an analog of folate, MTX is a powerful competitive inhibitor with 1000-fold more potent than the natural substrate of DHFR. DHFR is responsible for converting dihydrofolate (FH2) to their active form tetrahydrofolate (FH4), which is a substrate of thymidylate synthase (TS). Second, MTX is converted to active methotrexate polyglutamates (MTX-PGs) by folylpolyglutamate synthase $[11,12]$. The polyglutamated forms of MTX inhibit TS directly. Due to these inhibitions, 
TABLE 1: Experimental pIC50 values for DHFR inhibitors [40].

\begin{tabular}{|c|c|c|c|c|c|}
\hline Name & R1 & $\mathrm{R} 2$ & $X$ & R3 & pIC50 \\
\hline 1 & $\mathrm{CH}_{3}$ & $\mathrm{CH}_{3}$ & $\mathrm{CH}_{2}$ & $\mathrm{H}$ & 4.71 \\
\hline 2 & $\mathrm{CH}_{3}$ & $\mathrm{CH}_{3}$ & $\mathrm{CH}_{2}$ & $4^{\prime}-\mathrm{CH}_{3}$ & 4.6091 \\
\hline $3^{*}$ & $\mathrm{CH}_{3}$ & $\mathrm{CH}_{3}$ & $\mathrm{CH}_{2}$ & $4^{\prime}-\mathrm{OCH}_{3}$ & 4.2306 \\
\hline 4 & $\mathrm{CH}_{3}$ & $\mathrm{CH}_{3}$ & $\mathrm{CH}_{2}$ & $4^{\prime}-\mathrm{F}$ & 4.6615 \\
\hline $5^{*}$ & $\mathrm{CH}_{3}$ & $\mathrm{CH}_{3}$ & $\mathrm{CH}_{2}$ & $4^{\prime}-\mathrm{Cl}$ & 4.5243 \\
\hline 6 & $\mathrm{CH}_{3}$ & $\mathrm{CH}_{3}$ & $\mathrm{CH}_{2}$ & $3^{\prime}, 4^{\prime}-\mathrm{diCl}$ & 4.8928 \\
\hline $7^{*}$ & $\mathrm{CH}_{3}$ & $\mathrm{CH}_{3}$ & $-\mathrm{O}-\mathrm{CH}_{2}-$ & $\mathrm{H}$ & 7.1612 \\
\hline 8 & $\mathrm{CH}_{3}$ & $\mathrm{C}_{2} \mathrm{H}_{5}$ & $-\mathrm{O}-\mathrm{CH}_{2}-$ & $\mathrm{H}$ & 6.8097 \\
\hline $9^{*}$ & $\mathrm{H}$ & $\mathrm{c}-\mathrm{Pr}$ & $-\mathrm{O}-\mathrm{CH}_{2}-$ & $\mathrm{H}$ & 6.2612 \\
\hline 10 & $-\left(\mathrm{CH}_{2}\right)_{3}-$ & & $-\mathrm{O}-\mathrm{CH}_{2}-$ & $\mathrm{H}$ & 6.8729 \\
\hline 11 & $-\left(\mathrm{CH}_{2}\right)_{4}-$ & & $-\mathrm{O}-\mathrm{CH}_{2}-$ & $\mathrm{H}$ & 6.762 \\
\hline 12 & $-\left(\mathrm{CH}_{2}\right)_{5}-$ & & $-\mathrm{O}-\mathrm{CH}_{2}-$ & $\mathrm{H}$ & 5.7471 \\
\hline 13 & $-\left(\mathrm{CH}_{2}\right)_{6}-$ & & $-\mathrm{O}-\mathrm{CH}_{2}-$ & $\mathrm{H}$ & 5.2733 \\
\hline 14 & $-\left(\mathrm{CH}_{2}\right)_{4}-$ & & $-\mathrm{O}-\mathrm{CH}_{2} \mathrm{CH}_{2}-$ & $\mathrm{H}$ & 7.5086 \\
\hline 15 & $-\left(\mathrm{CH}_{2}\right)_{5}^{-}$ & & $-\mathrm{O}-\mathrm{CH}_{2} \mathrm{CH}_{2}-$ & $\mathrm{H}$ & 8.0458 \\
\hline 16 & $-\left(\mathrm{CH}_{2}\right)_{4}-$ & & $-\mathrm{O}-\left(\mathrm{CH}_{2}\right)_{3}-\mathrm{O}-$ & $\mathrm{H}$ & 7.699 \\
\hline 17 & $-\left(\mathrm{CH}_{2}\right)_{5}^{-}$ & & $-\mathrm{O}-\left(\mathrm{CH}_{2}\right)_{3}-\mathrm{O}-$ & $\mathrm{H}$ & 7.4949 \\
\hline 18 & $\mathrm{CH}_{3}$ & $\mathrm{CH}_{3}$ & $-\mathrm{O}-\left(\mathrm{CH}_{2}\right)_{3}-\mathrm{O}-$ & $\mathrm{H}$ & 8.2218 \\
\hline 19 & $\mathrm{CH}_{3}$ & $\mathrm{CH}_{3}$ & $-\mathrm{O}-\left(\mathrm{CH}_{2}\right)_{4}-\mathrm{O}-$ & $\mathrm{H}$ & 7.5686 \\
\hline 20 & $\mathrm{CH}_{3}$ & $\mathrm{C}_{2} \mathrm{H}_{5}$ & $-\mathrm{O}-\left(\mathrm{CH}_{2}\right)_{3}-\mathrm{O}-$ & $\mathrm{H}$ & 8.0969 \\
\hline 21 & $\mathrm{H}$ & $c-\operatorname{Pr}$ & $-\mathrm{O}-\left(\mathrm{CH}_{2}\right)_{3}-\mathrm{O}-$ & $\mathrm{H}$ & 8.1549 \\
\hline 22 & $-\left(\mathrm{CH}_{2}\right)_{4}-$ & & $-\mathrm{O}-\left(\mathrm{CH}_{2}\right)_{3}-\mathrm{O}-$ & $\mathrm{H}$ & 8.699 \\
\hline $23^{*}$ & $-\left(\mathrm{CH}_{2}\right)_{4}-$ & & $-\mathrm{O}-\left(\mathrm{CH}_{2}\right)_{4}-\mathrm{O}-$ & $\mathrm{H}$ & 7.3768 \\
\hline 24 & $-\left(\mathrm{CH}_{2}\right)_{5}^{-}$ & & $-\mathrm{O}-\left(\mathrm{CH}_{2}\right)_{3}-\mathrm{O}-$ & $\mathrm{H}$ & 8.1549 \\
\hline 25 & $-\left(\mathrm{CH}_{2}\right)_{5}-$ & & $-\mathrm{O}-\left(\mathrm{CH}_{2}\right)_{4}-\mathrm{O}-$ & $\mathrm{H}$ & 6.8069 \\
\hline 26 & $-\left(\mathrm{CH}_{2}\right)_{6}-$ & & $-\mathrm{O}-\left(\mathrm{CH}_{2}\right)_{3}-\mathrm{O}-$ & $\mathrm{H}$ & 7.9586 \\
\hline 27 & $-\left(\mathrm{CH}_{2}\right)_{5}-$ & & $-\mathrm{O}-\left(\mathrm{CH}_{2}\right)_{3}-\mathrm{O}-$ & $\mathrm{F}$ & 7.8239 \\
\hline 28 & $-\left(\mathrm{CH}_{2}\right)_{5}-$ & & $-\mathrm{O}-\left(\mathrm{CH}_{2}\right)_{3}-\mathrm{O}-$ & $\mathrm{Cl}$ & 7.8539 \\
\hline 29 & $-\left(\mathrm{CH}_{2}\right)_{5}-$ & & $-\mathrm{O}-\left(\mathrm{CH}_{2}\right)_{3}-\mathrm{O}-$ & $\mathrm{NO}_{2}$ & 7.8239 \\
\hline 30 & $-\left(\mathrm{CH}_{2}\right)_{5}-$ & & $-\mathrm{O}-\left(\mathrm{CH}_{2}\right)_{3}-\mathrm{O}-$ & $\mathrm{Me}$ & 7.7447 \\
\hline 31 & $-\left(\mathrm{CH}_{2}\right)_{5}-$ & & $-\mathrm{O}-\left(\mathrm{CH}_{2}\right)_{3}-\mathrm{O}-$ & $\mathrm{t}-\mathrm{Bu}$ & 7.6576 \\
\hline 32 & $-\left(\mathrm{CH}_{2}\right)_{5}-$ & & $-\mathrm{O}-\left(\mathrm{CH}_{2}\right)_{3}-\mathrm{O}-$ & $\mathrm{OMe}$ & 8.2218 \\
\hline $33^{*}$ & $-\left(\mathrm{CH}_{2}\right)_{5}-$ & & $-\mathrm{O}-\left(\mathrm{CH}_{2}\right)_{3}-\mathrm{O}-$ & $\mathrm{CN}$ & 8 \\
\hline 34 & $-\left(\mathrm{CH}_{2}\right)_{5}-$ & & $-\mathrm{O}-\left(\mathrm{CH}_{2}\right)_{3}-\mathrm{O}-$ & $\mathrm{COCH}_{3}$ & 7.8861 \\
\hline 35 & $-\left(\mathrm{CH}_{2}\right)_{5}-$ & & $-\mathrm{O}-\left(\mathrm{CH}_{2}\right)_{3}-\mathrm{O}-$ & $\mathrm{SO}_{2} \mathrm{NH}_{2}$ & 8.2218 \\
\hline $36^{*}$ & $-\left(\mathrm{CH}_{2}\right)_{4}-$ & & $-\mathrm{O}-\left(\mathrm{CH}_{2}\right)_{3}-\mathrm{O}-$ & F & 8 \\
\hline 37 & $-\left(\mathrm{CH}_{2}\right)_{4}^{-}$ & & $-\mathrm{O}-\left(\mathrm{CH}_{2}\right)_{3}-\mathrm{O}-$ & $\mathrm{Cl}$ & 8.1549 \\
\hline 38 & $-\left(\mathrm{CH}_{2}\right)_{4}-$ & & $-\mathrm{O}-\left(\mathrm{CH}_{2}\right)_{3}-\mathrm{O}-$ & $\mathrm{NO}_{2}$ & 8.0969 \\
\hline $39^{*}$ & $-\left(\mathrm{CH}_{2}\right)_{4}-$ & & $-\mathrm{O}-\left(\mathrm{CH}_{2}\right)_{3}-\mathrm{O}-$ & $\mathrm{Me}$ & 8 \\
\hline 40 & $-\left(\mathrm{CH}_{2}\right)_{4}-$ & & $-\mathrm{O}-\left(\mathrm{CH}_{2}\right)_{3}-\mathrm{O}-$ & $\mathrm{t}-\mathrm{Bu}$ & 7.7696 \\
\hline 41 & $-\left(\mathrm{CH}_{2}\right)_{4}-$ & & $-\mathrm{O}-\left(\mathrm{CH}_{2}\right)_{3}-\mathrm{O}-$ & $\mathrm{OMe}$ & 7.9586 \\
\hline 42 & $-\left(\mathrm{CH}_{2}\right)_{4}-$ & & $-\mathrm{O}-\left(\mathrm{CH}_{2}\right)_{3}-\mathrm{O}-$ & $\mathrm{CN}$ & 8.0969 \\
\hline 43 & $-\left(\mathrm{CH}_{2}\right)_{4}-$ & & $-\mathrm{O}-\left(\mathrm{CH}_{2}\right)_{3}-\mathrm{O}-$ & $\mathrm{COCH}_{3}$ & 8.0458 \\
\hline $44^{*}$ & $-\left(\mathrm{CH}_{2}\right)_{4}-$ & & $-\mathrm{O}-\left(\mathrm{CH}_{2}\right)_{3}-\mathrm{N}(\mathrm{Me})-$ & $\mathrm{H}$ & 7.3872 \\
\hline 45 & $-\left(\mathrm{CH}_{2}\right)_{4}-$ & & $-\mathrm{O}-\left(\mathrm{CH}_{2}\right)_{3}-$ & $\mathrm{H}$ & 7.4949 \\
\hline MTX & & & & & 8.5229 \\
\hline
\end{tabular}

* test set.

the cells will not be capable of de novo synthesis of purines and thymidylate, and thus DNA synthesis will be inhibited [13].

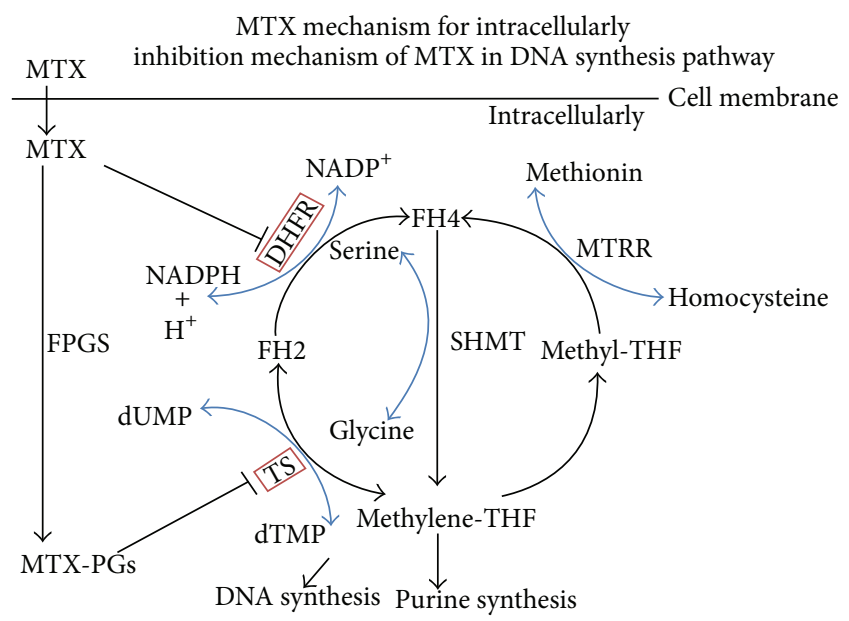

FIGURE 1: Inhibition mechanism of MTX in DNA synthesis pathway. MTX: methotrexate; FPGS: folylpolyglutamate synthetase; MTXPGs: methotrexate polyglutamates; DHFR: dihydrofolate reductase; TS: thymidylate synthase; FH4: tetrahydrofolate; FH2: dihydrofolate; Methylene-THF: 5,10-methylenetetrahydrofolate; MethylTHF: 5-methyltetrahydrofolate; dUMP: deoxyurindine- 5 '-monophosphate; dTMP: deoxythymidine $-5^{\prime}$-monophosphate; MTRR: methionine synthase reductase; SHMT: serine hydroxymethyltransferase.

The primary action of MTX is inhibition of the enzyme DHFR, which converts dihydrofolate (FH2) to tetrahydrofolate (FH4) [11, 14]. MTX-PGs exert a stronger inhibition of DHFR and TS [15-17]. Thus, through direct inhibition by MTX and due to lack of FH4 and accumulation of FH2, deoxythymidine monophosphate synthesis and purine de novo synthesis is blocked, which eventually lead to leukemic cell death, bone marrow suppression, gastrointestinal mucositis, liver toxicity, and, rarely, alopecia [14, $15,18,19]$. In fact, both MTX and natural folates undergo polyglutamylation catalyzed by the enzyme folylpolyglutamyl synthase. The MTX-PGs ensure intracellular retention and, furthermore, increase the affinity for the MTX-sensitive enzymes $[16,18,20]$ (Figure 1).

However, MTX may lead to acute renal cytotoxicity [21] which is serious and potentially fatal in the spinal canal and may occur after the administration of neurotoxicity [22-25] and hematological toxicity [26] caused by animal somatic cells and human bone marrow chromosomal lesions [27] which led to the hematopoietic system abnormalities [28], gastrointestinal toxicity [29] made multiorgan dysfunction [30], nephrotoxicity [31] made renal failure [31, 32], and hepatotoxicity made liver fibrosis [33]. Higher concentrations of long-chain MTX-PGs have been in the risk of gastrointestinal and hepatic toxicity $[12,34,35]$. Thus, the lower toxicity drugs are necessary to be developed. Recently, the increasing numbers of mechanisms of different diseases have been clarified to detect the helpful target protein for diseases treatment [36-49], and diseases treatments with traditional Chinese medicine (TCM) as complements are getting more and more attention. The compounds extracted from traditional Chinese medicine have displayed their potential as 
TABLE 2: DHFR and TS docking score of TCM candidates.

\begin{tabular}{lccc}
\hline Index & TCM candidate & DHFR docking score & TS docking score \\
\hline 1 & Adenosine triphosphate & 226.6790 & 186.2170 \\
2 & Methyl 6-O-digalloyl-beta-D-glucopyranoside (II) & 162.6260 & 154.1730 \\
3 & Methyl 4,6-di-O-galloyl-beta-D-glucopyranoside & 153.7500 & 148.2880 \\
4 & Methyl 6-O-digalloyl-beta-D-glucopyranoside & 151.7650 & 158.0350 \\
5 & Manninotriose & 129.7870 & 114.6030 \\
6 & Forsythiaside & 129.6030 & 27.9940 \\
7 & Isoacteoside & 124.5900 & 30.6190 \\
8 & Rehmannioside B & 119.9930 & 79.2920 \\
9 & Rehmannioside A & 116.4330 & 71.3970 \\
10 & Raffinose & 115.4940 & 134.2120 \\
11 & Cistanoside C & 112.4270 & - \\
12 & Methyl 3,3,6-tri-O-galloyl-beta-D-glucopyranoside & 109.9470 & 20.7830 \\
13 & Stachyose & 107.0940 & 8.5760 \\
14 & Chlorogenic acid & 103.8080 & - \\
15 & Jionoside D & 103.5050 & 39.3430 \\
16 & Isochlorogenic acid & 102.9470 & - \\
17 & Jionoside C & 102.3940 & - \\
18 & Rutin & 101.1310 & 78.816 \\
$* *$ & MTX & 97.0960 & - \\
$*$ & MTX-PGs & - & 69.671 \\
\hline
\end{tabular}

* control.

${ }^{* *}$ Methotrexate polyglutamate.

TABLE 3: Predicted pharmacokinetic properties of TCM candidates and MTX.

\begin{tabular}{|c|c|c|c|c|c|}
\hline \multirow{2}{*}{ Index } & \multirow{2}{*}{ TCM candidate } & \multicolumn{4}{|c|}{ Pharmacokinetic properties } \\
\hline & & Absorption & Solubility & Hepatotoxicity & PPB \\
\hline 1 & Adenosine triphosphate & 3 & 2 & 1 & 0 \\
\hline 2 & Chlorogenic acid & 3 & 4 & 1 & 0 \\
\hline 3 & Cistanoside C & 3 & 2 & 1 & 2 \\
\hline 4 & Forsythiaside & 3 & 2 & 1 & 0 \\
\hline 5 & Isoacteoside & 3 & 2 & 1 & 0 \\
\hline 6 & Isochlorogenic acid & 3 & 4 & 1 & 0 \\
\hline 7 & Jionoside C & 3 & 3 & 1 & 2 \\
\hline 8 & Jionoside D & 3 & 2 & 1 & 2 \\
\hline 9 & Manninotriose & 3 & 3 & 0 & 0 \\
\hline 10 & Methyl 4,6-di-O-galloyl-beta-D-glucopyranoside & 3 & 2 & 1 & 0 \\
\hline 11 & Methyl 6-O-digalloyl-beta-D-glucopyranoside & 3 & 2 & 1 & 0 \\
\hline 12 & Methyl 6-O-digalloyl-beta-D-glucopyranoside (II) & 3 & 2 & 1 & 0 \\
\hline 13 & Methyl 3,3,6-tri-O-galloyl-beta-D-glucopyranoside & 3 & 0 & 1 & 0 \\
\hline 14 & Raffinose & 3 & 3 & 0 & 0 \\
\hline 15 & Rehmannioside A & 3 & 4 & 1 & 0 \\
\hline 16 & Rehmannioside B & 3 & 4 & 1 & 0 \\
\hline 17 & Rutin & 3 & 1 & 1 & 2 \\
\hline 18 & Stachyose & 3 & 1 & 0 & 0 \\
\hline Control & MTX & 3 & 3 & 1 & 1 \\
\hline
\end{tabular}

${ }^{1}$ Absorption (Human intestinal absorption), there are four prediction levels: 0 (good absorption), 1 (moderate absorption), 2 (poor absorption), 3 (very poor absorption).

${ }^{2}$ Solubility, there are gour prediction levels: 0 (extremely low), 1 (very low, but possible), 2 (low), 3 (good), 4 (optimal), 5 (too soluble), 6 (warning).

${ }^{3}$ Hepatotoxicity, there are four prediction levels: 0 (nontoxic), 1 (toxic).

${ }^{4} \mathrm{PPB}$ (Plasma protein binding), there are there prediction levels: 0 (binding is $<90 \%$ ), 1 (binding is $>90 \%$ ), 2 (binding $>95 \%$ ). 
TABLE 4: Partial Least Square (PLS) analysis for CoMFA and CoMSIA models.

\begin{tabular}{|c|c|c|c|c|c|c|c|c|c|c|}
\hline & \multicolumn{2}{|c|}{ Cross Validation } & \multicolumn{3}{|c|}{ Non-cross Validtion } & \multicolumn{5}{|c|}{ Fraction } \\
\hline & ONC & $q^{2}$ & $r^{2}$ & SEE & F & $S$ & $\mathrm{E}$ & $\mathrm{H}$ & $\mathrm{D}$ & A \\
\hline \multicolumn{11}{|c|}{ CoMFA } \\
\hline & 7 & 0.5250 & 0.9630 & 0.2590 & 136.2760 & 0.7970 & 0.2030 & - & - & - \\
\hline \multicolumn{11}{|c|}{ CoMSIA } \\
\hline S & 36 & 0.6350 & 0.9890 & 0.3040 & 19.6900 & 1.0000 & 0.0000 & 0.0000 & 0.0000 & 0.0000 \\
\hline $\mathrm{E}$ & - & - & - & - & - & - & - & - & - & - \\
\hline $\mathrm{H}$ & 2 & 0.6130 & 0.7760 & 0.5940 & 72.7070 & 0.0000 & 0.0000 & 1.0000 & 0.0000 & 0.0000 \\
\hline $\mathrm{D}$ & 7 & 0.4180 & 0.7160 & 0.7130 & 13.3480 & 0.0000 & 0.0000 & 0.0000 & 1.0000 & 0.0000 \\
\hline A & 1 & 0.0810 & 0.1600 & 1.1380 & 8.1640 & 0.0000 & 0.0000 & 0.0000 & 0.0000 & 1.0000 \\
\hline SE & 37 & 0.6050 & 0.9890 & 0.3250 & 16.7260 & 0.9980 & 0.0200 & 0.0000 & 0.0000 & 0.0000 \\
\hline $\mathrm{SH}$ & 2 & 0.5970 & 0.7790 & 0.5910 & 73.9120 & 0.3880 & 0.0000 & 0.6120 & 0.0000 & 0.0000 \\
\hline SD & 36 & 0.6670 & 0.9890 & 0.3020 & 19.9580 & 0.6350 & 0.0000 & 0.0000 & 0.3650 & 0.0000 \\
\hline SA & 30 & 0.7020 & 0.9890 & 0.2340 & 39.7820 & 0.7480 & 0.0000 & 0.0000 & 0.0000 & 0.2520 \\
\hline $\mathrm{EH}$ & 7 & 0.6270 & 0.9540 & 0.2860 & 110.4680 & 0.0000 & 0.0500 & 0.9500 & 0.0000 & 0.0000 \\
\hline $\mathrm{ED}$ & 7 & 0.4130 & 0.7090 & 0.7210 & 12.9020 & 0.0000 & 0.0180 & 0.0000 & 0.9820 & 0.0000 \\
\hline EA & 2 & 0.0760 & 0.1830 & 1.1350 & 4.6860 & 0.0000 & 0.2000 & 0.0000 & 0.0000 & 0.8000 \\
\hline HD & 2 & 0.5780 & 0.7940 & 0.5690 & 81.1680 & 0.0000 & 0.0000 & 0.7220 & 0.2780 & 0.0000 \\
\hline HA & 2 & 0.5890 & 0.7910 & 0.5740 & 79.5410 & 0.0000 & 0.0000 & 0.7450 & 0.0000 & 0.2550 \\
\hline DA & 9 & 0.4300 & 0.7290 & 0.7160 & 10.4430 & 0.0000 & 0.0000 & 0.0000 & 0.7800 & 0.2200 \\
\hline SHE & 8 & 0.5850 & 0.9690 & 0.2400 & 139.5820 & 0.3570 & 0.0440 & 0.6000 & 0.0000 & 0.0000 \\
\hline SED & 38 & 0.6500 & 0.9890 & 0.3490 & 14.1810 & 0.6340 & 0.0010 & 0.0000 & 0.3650 & 0.0000 \\
\hline SEA & 31 & 0.7030 & 0.9880 & 0.2430 & 35.7980 & 0.7420 & 0.0110 & 0.0000 & 0.0000 & 0.2470 \\
\hline SHD & 22 & 0.5780 & 0.9890 & 0.1830 & 89.3410 & 0.3070 & 0.0000 & 0.4490 & 0.2430 & 0.0000 \\
\hline SHA & 2 & 0.5800 & 0.7950 & 0.5680 & 81.4850 & 0.3130 & 0.0000 & 0.4980 & 0.0000 & 0.1900 \\
\hline SDA & 30 & 0.7170 & 0.9890 & 0.2320 & 40.3890 & 0.5640 & 0.0000 & 0.0000 & 0.2910 & 0.1450 \\
\hline EDA & 11 & 0.4240 & 0.7380 & 0.7250 & 8.4650 & 0.0000 & 0.0200 & 0.0000 & 0.7640 & 0.2150 \\
\hline EHA $^{*}$ & 11 & 0.5770 & 0.9800 & 0.1990 & 148.9890 & 0.0000 & 0.0630 & 0.6910 & 0.0000 & 0.2460 \\
\hline HAD & 2 & 0.5550 & 0.8020 & 0.5580 & 85.2150 & 0.0000 & 0.0000 & 0.6150 & 0.2080 & 0.1770 \\
\hline SEHD & 23 & 0.5970 & 0.9890 & 0.1870 & 81.1730 & 0.2940 & 0.0230 & 0.4520 & 0.2310 & 0.0000 \\
\hline SEHA & 23 & 0.5970 & 0.9800 & 0.1880 & 80.4080 & 0.3000 & 0.0420 & 0.4620 & 0.0000 & 0.1960 \\
\hline SEDA & 31 & 0.7110 & 0.9890 & 0.2420 & 36.1870 & 0.5640 & 0.0050 & 0.0000 & 0.2840 & 0.1470 \\
\hline SHDA & 5 & 0.5630 & 0.9290 & 0.3470 & 102.3970 & 0.2600 & 0.0000 & 0.3980 & 0.1920 & 0.1510 \\
\hline EHDA $^{*}$ & 12 & 0.6070 & 0.9820 & 0.1940 & 143.5670 & 0.0000 & 0.0500 & 0.5880 & 0.2040 & 0.1580 \\
\hline SEHDA & 23 & 0.6120 & 0.9890 & 0.1880 & 80.3300 & 0.2690 & 0.0340 & 0.4020 & 0.1630 & 0.1330 \\
\hline
\end{tabular}

OCN: Optimal number of components.

SEE: Standard error of estimate.

$F$ : $F$-test value.

* Prediction model.

S: Steric.

H: Hydrophobic.

D: Hydrogen bond donor.

A: Hydrogen bone acceptor.

E: Electrostatic.

lead compounds against tumors [50-54], stroke [55-58], viral infection [59-63], metabolic syndrome [64-66], diabetes [67], inflammation [62], and other diseases [68, 69]. For this trend, we attempted to discover the compounds with druglike potential and lower toxicity for ALL treatment from the components in traditional Chinese medicine.

\section{Materials and Methods}

2.1. Virtual Screening. The receptors, human dihydrofolate reductase (DHFR) and human thymidylate synthase (TS) proteins were downloaded from Protein Data Bank of 1 U72 (PDB ID: 1U72) [70] and 1HVY (PDB ID: 1HVY) [71]. 
TABLE 5: Experimental and predicted pIC50 values of 45 DHFR inhibitors using the constructed CoMFA and CoMSIA models.

\begin{tabular}{|c|c|c|c|c|c|c|c|}
\hline \multirow{2}{*}{ DHFR inhibitors no. } & \multirow{2}{*}{ Experimental pIC50 } & \multicolumn{2}{|c|}{ CoMFA } & \multicolumn{2}{|c|}{ CoMSIA_EHDA } & \multicolumn{2}{|c|}{ CoMSIA_EHA } \\
\hline & & Predicted & Residual & Predicted & Residual & Predicted & Residual \\
\hline 1 & 4.710 & 4.652 & 0.0580 & 4.481 & 0.229 & 4.532 & 0.178 \\
\hline 2 & 4.609 & 4.606 & 0.0031 & 4.635 & -0.026 & 4.662 & -0.053 \\
\hline $3^{*}$ & 4.231 & 4.576 & -0.3454 & 4.333 & -0.102 & 4.407 & -0.176 \\
\hline 4 & 4.662 & 5.027 & -0.3655 & 4.698 & -0.037 & 4.701 & -0.039 \\
\hline $5^{*}$ & 4.524 & 4.571 & -0.0467 & 4.807 & -0.283 & 4.797 & -0.273 \\
\hline 6 & 4.893 & 4.476 & 0.4168 & 4.723 & 0.170 & 4.651 & 0.242 \\
\hline $7^{*}$ & 7.161 & 6.810 & 0.3512 & 7.287 & -0.126 & 7.359 & -0.198 \\
\hline 8 & 6.810 & 6.529 & 0.2807 & 6.722 & 0.088 & 6.723 & 0.087 \\
\hline $9^{*}$ & 6.261 & 6.495 & -0.2338 & 6.270 & -0.009 & 6.240 & 0.021 \\
\hline 10 & 6.873 & 6.648 & 0.2249 & 6.808 & 0.065 & 6.832 & 0.041 \\
\hline 11 & 6.762 & 6.793 & -0.0310 & 6.686 & 0.076 & 6.645 & 0.117 \\
\hline 12 & 5.747 & 5.749 & -0.0019 & 5.767 & -0.020 & 5.705 & 0.042 \\
\hline 13 & 5.273 & 5.346 & -0.0727 & 5.245 & 0.028 & 5.279 & -0.006 \\
\hline 14 & 7.509 & 7.454 & 0.0546 & 7.494 & 0.015 & 7.522 & -0.013 \\
\hline 15 & 8.046 & 8.322 & -0.2762 & 8.056 & -0.010 & 8.052 & -0.006 \\
\hline 16 & 7.699 & 8.127 & -0.4280 & 8.130 & -0.431 & 8.110 & -0.411 \\
\hline 17 & 7.495 & 7.670 & -0.1751 & 7.871 & -0.376 & 7.820 & -0.325 \\
\hline 18 & 8.222 & 8.079 & 0.1428 & 8.130 & 0.092 & 8.105 & 0.117 \\
\hline 19 & 7.569 & 7.561 & 0.0076 & 7.581 & -0.012 & 7.609 & -0.040 \\
\hline 20 & 8.097 & 8.207 & -0.1101 & 8.105 & -0.008 & 8.240 & -0.143 \\
\hline 21 & 8.155 & 8.007 & 0.1479 & 8.242 & -0.087 & 8.215 & -0.060 \\
\hline 22 & 8.699 & 8.127 & 0.5720 & 8.130 & 0.569 & 8.110 & 0.589 \\
\hline $23^{*}$ & 7.377 & 7.636 & -0.2592 & 7.325 & 0.052 & 7.318 & 0.059 \\
\hline 24 & 8.155 & 7.670 & 0.4849 & 7.871 & 0.284 & 7.820 & 0.335 \\
\hline 25 & 6.807 & 7.113 & -0.3061 & 6.902 & -0.095 & 6.824 & -0.017 \\
\hline 26 & 7.959 & 7.987 & -0.0284 & 7.887 & 0.072 & 7.975 & -0.016 \\
\hline 27 & 7.824 & 7.763 & 0.0609 & 7.981 & -0.157 & 7.955 & -0.131 \\
\hline 28 & 7.854 & 7.839 & 0.0149 & 7.906 & -0.052 & 7.850 & 0.004 \\
\hline 29 & 7.824 & 7.843 & -0.0191 & 7.824 & 0.000 & 7.827 & -0.003 \\
\hline 30 & 7.745 & 7.914 & -0.1693 & 7.736 & 0.009 & 7.733 & 0.012 \\
\hline 31 & 7.658 & 8.069 & -0.4114 & 7.665 & -0.007 & 7.654 & 0.004 \\
\hline 32 & 8.222 & 8.005 & 0.2168 & 7.848 & 0.374 & 7.814 & 0.408 \\
\hline $33^{*}$ & 8.000 & 8.100 & -0.1000 & 7.978 & 0.022 & 8.010 & -0.010 \\
\hline 34 & 7.886 & 7.455 & 0.4311 & 7.947 & -0.061 & 7.811 & 0.075 \\
\hline 35 & 8.222 & 7.981 & 0.2408 & 8.208 & 0.014 & 8.237 & -0.015 \\
\hline $36^{*}$ & 8.000 & 8.173 & -0.1730 & 8.130 & -0.130 & 8.139 & -0.139 \\
\hline 37 & 8.155 & 8.180 & -0.0251 & 8.170 & -0.015 & 8.187 & -0.032 \\
\hline 38 & 8.097 & 8.122 & -0.0251 & 8.097 & 0.000 & 8.097 & 0.000 \\
\hline $39^{*}$ & 8.000 & 7.990 & 0.0100 & 8.007 & -0.007 & 8.054 & -0.054 \\
\hline 40 & 7.770 & 7.683 & 0.0866 & 7.832 & -0.062 & 7.697 & 0.073 \\
\hline 41 & 7.959 & 8.223 & -0.2644 & 7.883 & 0.076 & 7.907 & 0.052 \\
\hline 42 & 8.097 & 7.974 & 0.1229 & 8.040 & 0.057 & 8.150 & -0.053 \\
\hline 43 & 8.046 & 7.996 & 0.0498 & 8.052 & -0.006 & 8.061 & -0.015 \\
\hline $44^{*}$ & 7.387 & 7.542 & -0.1548 & 7.567 & -0.180 & 7.590 & -0.203 \\
\hline 45 & 7.495 & 7.449 & 0.0459 & 7.484 & 0.011 & 7.516 & -0.021 \\
\hline
\end{tabular}

${ }^{*}$ test set. 
TAble 6: Predicted bioactivity (pIC50) of MTX and TCM candidates using MLR, Bayesian, SVM, CoMFA and CoMSIA models.

\begin{tabular}{|c|c|c|c|c|c|c|}
\hline Name & MLR & Bayesian & SVM & CoMFA & CoMSIA_EHDA* $^{*}$ & CoMSIA_EHA $^{* *}$ \\
\hline Adenosine triphosphate & 6.4559 & 5.8145 & 8.7175 & 7.9640 & 7.8600 & 7.8350 \\
\hline Methyl 6-O-digalloyl-beta-D-glucopyranoside (II) & 27.5044 & 5.1810 & 8.0157 & 6.9800 & 6.6030 & 5.5170 \\
\hline Methyl 4,6-di-O-galloyl-beta-D-glucopyranoside & 27.7317 & 5.4868 & 8.4131 & 7.5490 & 6.5980 & 5.9300 \\
\hline Methyl 6-O-digalloyl-beta-D-glucopyranoside & 26.7188 & 5.2477 & 7.8936 & 6.8980 & 6.6620 & 5.6840 \\
\hline Manninotriose & 29.1034 & 5.1934 & 5.9247 & 7.6470 & 6.2450 & 5.3700 \\
\hline Forsythiaside & 29.9821 & 5.3595 & 8.5713 & 7.7140 & 8.0830 & 7.8950 \\
\hline Isoacteoside & 27.6319 & 6.3265 & 8.1255 & 7.6550 & 7.7990 & 7.5430 \\
\hline Rehmannioside B & 26.7291 & 4.3032 & 7.3293 & 6.9990 & 6.8000 & 5.8300 \\
\hline Rehmannioside A & 30.3632 & 4.4182 & 9.3324 & 6.7480 & 5.8070 & 4.6750 \\
\hline Raffinose & 32.8592 & 5.1647 & 8.4766 & 6.9350 & 5.9620 & 4.2830 \\
\hline Cistanoside C & 26.1802 & 5.7174 & 8.2029 & 7.6060 & 8.0200 & 7.9640 \\
\hline Methyl 3,3,6-tri-O-galloyl-beta-D-glucopyranoside & 30.7405 & 6.0369 & 8.3193 & 6.7670 & 6.3240 & 6.6300 \\
\hline Stachyose & 40.5491 & 5.9779 & 8.5055 & 7.4300 & 5.6830 & 4.4510 \\
\hline Chlorogenic acid & 17.3951 & 4.2335 & 7.8897 & 7.8080 & 7.9640 & 7.7680 \\
\hline Jionoside D & 26.0421 & 5.5238 & 8.2089 & 7.5080 & 7.4900 & 7.2820 \\
\hline Isochlorogenic acid & 16.1484 & 4.4196 & 7.4839 & 7.1990 & 6.3590 & 6.4480 \\
\hline Jionoside C & 23.7203 & 5.6640 & 8.2741 & 7.7600 & 7.0800 & 6.9110 \\
\hline Rutin & 30.3096 & 5.6910 & 8.2465 & 6.5720 & 8.0190 & 7.6830 \\
\hline
\end{tabular}

The pIC50 experimental values of MTX was 8.5229.

* EHDA model of CoMSIA.

${ }^{* *}$ EHA model of CoMSIA.

We adopted the traditional Chinese medicine formulas that treat acute lymphoblastic leukemia from database "Shanghai Innovative Research Center of Traditional Chinese Medicine" (http://www.sirc-tcm.sh.cn/en/index.html) [72]. The component compounds of these formulas were integrated with the herbs data from the TCM Database@Taiwan [73] and became the ALL disease-specific compound library. Virtual screening of candidates from the compound library was conducted using the LigandFit Module of DS 2.5 under the Chemistry at HARvard Macromolecular Mechanics (CHARMm) force field. DockScore was selected as output values. Candidates were ranked according to DockScore and pharmacokinetic characteristics including absorption, solubility, blood brain barrier $(\mathrm{BBB})$, and plasma protein binding ( $\mathrm{PPB})$ were predicted by ADMET protocols for each candidate.

2.2. 2D-Quantitative Structure Activity Relationship (2DQSAR) Models. In this study, 45 candidates (Figure 2) with known experimental pIC50 values [74] that have inhibitory activities toward DHFR were used in the QSAR studies (Table 1). The 45 known inhibitors were randomly divided into a training set of 36 candidates and a test set of 9 candidates. The chemical structures of these candidates were drawn by ChemDraw Ultra 10.0 (CambridgeSoft Inc., USA) and transformed to 3D molecule models by Chem3D Ultra 10.0 (CambridgeSoft Inc., USA). Molecular descriptors for each candidate were calculated using the DS 2.5 Calculate Molecular Property Module. Genetic function approximation (GFA) model was used to select representative descriptors that correlated $\left(r^{2}>0.8\right)$ to bioactivity (pIC50) which were used

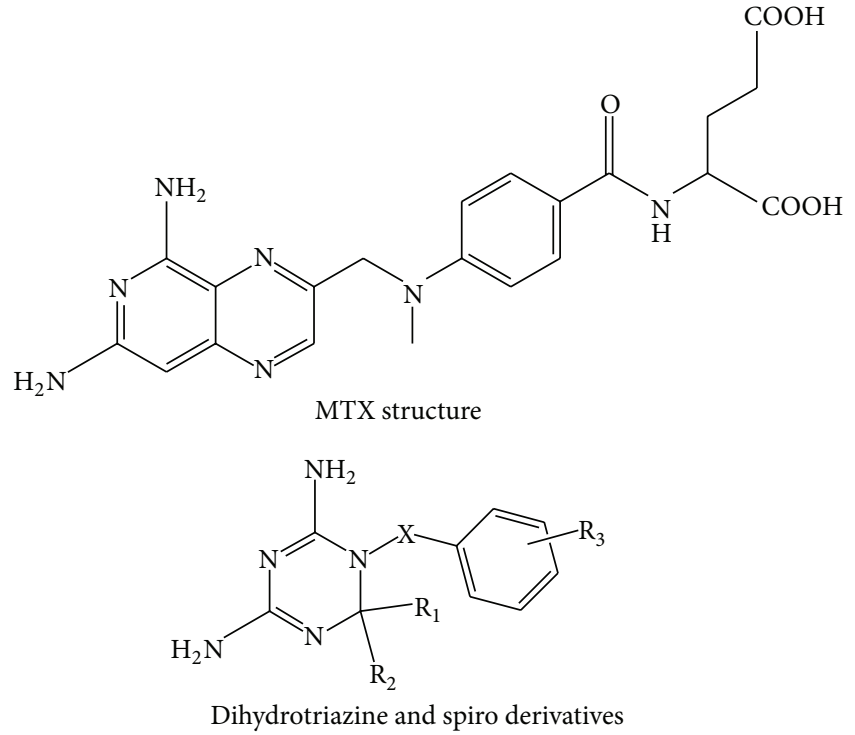

FIgURE 2: Chemical structure of DHFR inhibitors [40].

to construct 2D-QSAR models. The training set was used to construct multiple linear regression (MLR), support vector machine (SVM), and Bayesian network (BN) models. The test set was used to test the accuracy of these models.

2.2.1. Multiple Linear Regression (MLR) Model. Multiple linear regression [75] attempts to model the relationship between two or more explanatory variables and a response 


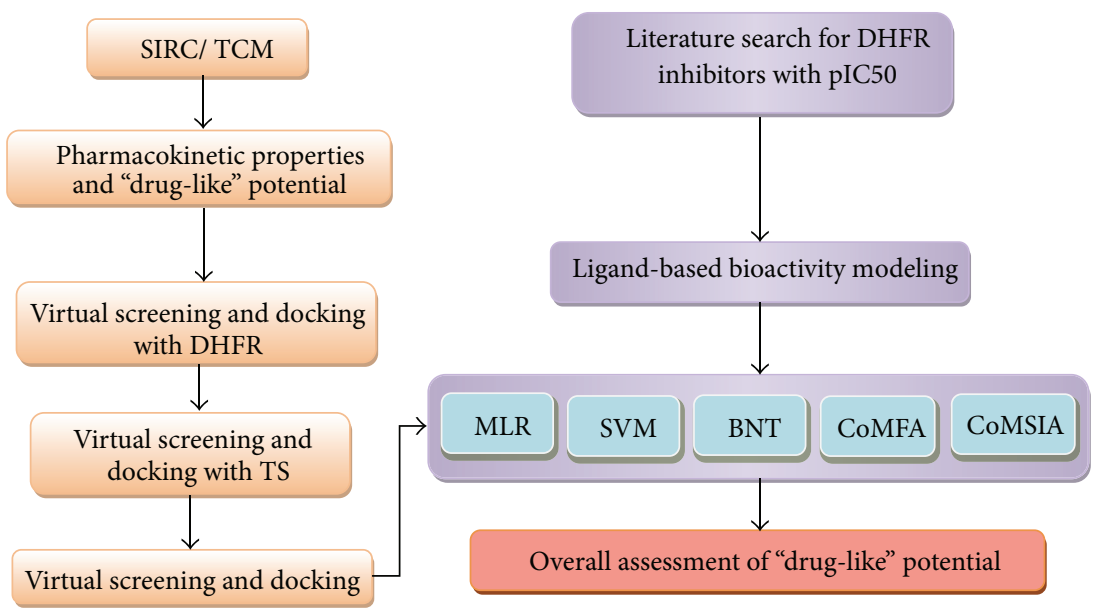

FIGURE 3: The experimental flowchart.

variable by fitting a linear equation to observed data. The model was built in the form of equation as follows:

$$
\mathrm{pIC}_{50}=a_{0}+a_{1} x_{1}+a_{2} x_{2}+\cdots+a_{n} x_{n}
$$

where $x_{i}$ represents the $i$ th molecular descriptor and $a_{i}$ is its fitting coefficient. The generated MLR model was validated with test dataset. The square correlation coefficients $\left(R^{2}\right)$ between predicted and actual pIC50 of the training set was used to verify accuracy of the model. This building model was applied to predict the pIC50 values of the TCM candidates.

2.2.2. Support Vector Machine (SVM) Model. SVM implement classification or regression analysis with linear or nonlinear algorithms [76]. The algorithm identifies a maximummargin hyper-plane to discriminate two class training samples. Samples on the margin are called the support vectors. Lagrange multipliers and kernels were introduced to form the final pattern separating regression model. In this study, LibSVM [77-79] package was selected to build our regression SVM model. The selected kernel was the Gaussian radial basis function kernel equation:

$$
K\left(x_{i}, x_{k}\right)=\exp \left[\frac{\left\|x_{i}-x_{k}\right\|^{2}}{2 \sigma^{2}}\right] .
$$

Cross-validation of the SVM model was also conducted following the default settings in LibSVM [80]. The generated regression SVM model was validated with test dataset. The square correlation coefficients $\left(R^{2}\right)$ between predicted and actual pIC50 of the training set was used to verify accuracy of the model. This building model was applied to predict the pIC50 values of the TCM candidates.

2.2.3. Bayesian Network Model. We used the Bayes Net Toolbox (BNT) in Matlab (https://code.google.com/p/bnt) to create Bayesian network model [81] by the training data set. After data discretization, we applied linear regression analysis for each pIC50 category in the training dataset. For the $i$ th pIC50 category with $n$ candidates, let $y_{i j}$ and $x_{i j p}$ represent the pIC50 value and the $p$ th descriptor value in the $j$ th ligand, respectively. The regression model of the data sets $\left\{y_{i j}, x_{i j 1}, \ldots, x_{i j p}\right\}_{j=1}^{n}$ is formulated as

$$
y_{i}=X_{i} \beta_{i}+\varepsilon_{i}
$$

where

$$
y_{i}=\left[\begin{array}{c}
y_{i 1} \\
y_{i 2} \\
\vdots \\
y_{i n}
\end{array}\right], \quad X_{i}=\left[\begin{array}{ccc}
x_{i 11} & \cdots & x_{i 1 p} \\
x_{i 21} & \cdots & x_{i 2 p} \\
\vdots & \vdots & \vdots \\
x_{i n 1} & \cdots & x_{i n p}
\end{array}\right] \text {, }
$$

and $\beta_{i}$ and $\varepsilon_{i}$ are the regression coefficients and error term in the $i$ th pIC50 category. We used ordinary least squares to estimate the unknown regression coefficient $\beta_{i}$ :

$$
\widehat{\beta}_{i}=\left(X_{i}^{T} X_{i}\right)^{-1} X_{i}^{T} y_{i}
$$

The Banjo (Bayesian network inference with Java objects) is software for structure learning of static Bayesian networks (BN) [82]. It is implemented in Java. We used training dataset to discover the relationships in the $\mathrm{BN}$ structure among the descriptors and the pIC50 by the Banjo package. After that, we used test data to assess the accuracy of our algorithm. For the test data $D$, the pIC50 category $(k)$ is predicted by the following formula:

$$
k=\arg \underset{i=1}{\stackrel{n}{\max }} P(i \mid D),
$$

where $i$ represented the $i$ th category of pIC50 and $n$ represented the total number of the pIC50 categories. The marginal probability $P(i \mid D)$ can be calculated by BNT module. Finally, the pIC50 value is calculated as follows:

$$
\mathrm{pIC50}=X_{k} \widehat{\beta}_{k}
$$




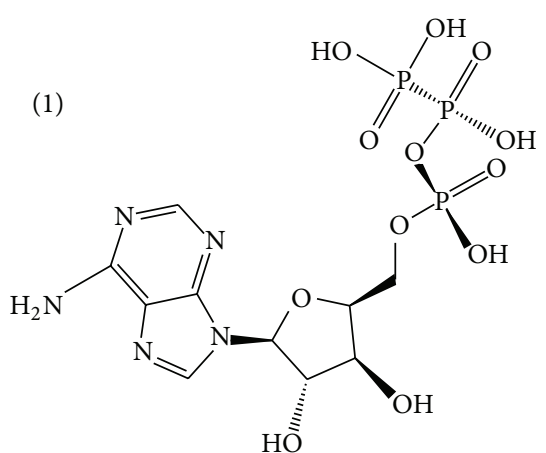

(3)<smiles>COC1O[C@H](COC(=O)c2cc(O)c(O)c(O)c2)[C@@H](OC(=O)c2cc(O)c(O)c(O)c2)[C@H](O)[C@H]1O</smiles>

(5)<smiles>OCC1O[C@H](OCC2O[C@H](OC[C@H]3OC(O)[C@H](O)[C@H](O)[C@H]3O)[C@@H](O)[C@H](O)[C@H]2O)[C@H](O)[C@@H](O)[C@H]1O</smiles>

(7)<smiles>C[C@@H]1O[C@H](O[C@H]2[C@H](O)[C@@H](COC(=O)/C=C\c3ccc(O)c(O)c3)O[C@@H](OCCc3ccc(O)c(O)c3)[C@@H]2O)[C@H](O)[C@@H](O)[C@@H]1O</smiles>

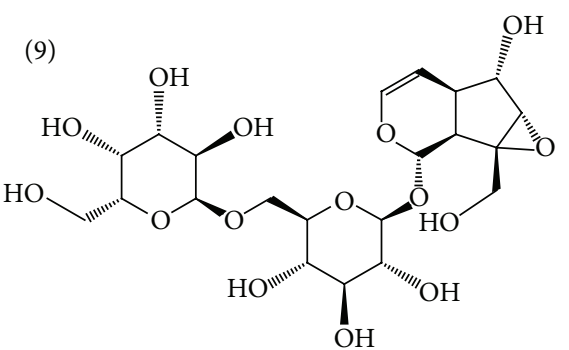

(2)<smiles>CO[C@H]1O[C@H](COC(=O)c2cc(O)c(O)c(OC(=O)c3cc(O)c(O)c(O)c3)c2)[C@H](O)[C@H](O)[C@@H]1O</smiles>

(4)<smiles>CO[C@H]1O[C@H](COC(=O)c2cc(O)c(OC(=O)c3cc(O)c(O)c(O)c3)c(O)c2)[C@H](O)[C@H](O)[C@@H]1O</smiles>

(6)<smiles>C[C@@H]1OC(OC[C@H]2O[C@H](OCCc3ccc(O)c(O)c3)[C@@H](O)[C@H](O)[C@H]2OC(=O)/C=C/c2ccc(O)c(O)c2)[C@H](O)[C@H](O)[C@H]1O</smiles>

(8)<smiles>OC[C@H]1O[C@@H](O[C@H]2OC=C[C@@H]3[C@@H]2[C@@H]2O[C@@]2(CO)[C@@H]3O[C@H]2O[C@H](CO)[C@@H](O)[C@H](O)[C@H]2O)[C@H](O)[C@@H](O)[C@@H]1O</smiles>

(10)<smiles>OC[C@H]1O[C@@](CO)(C2O[C@H](CO[C@H]3O[C@H](CO)[C@H](O)[C@H](O)[C@H]3O)[C@H](O)[C@@H](O)[C@H]2O)[C@H](O)[C@@H]1O</smiles>

(a)

FIgURE 4: Continued. 

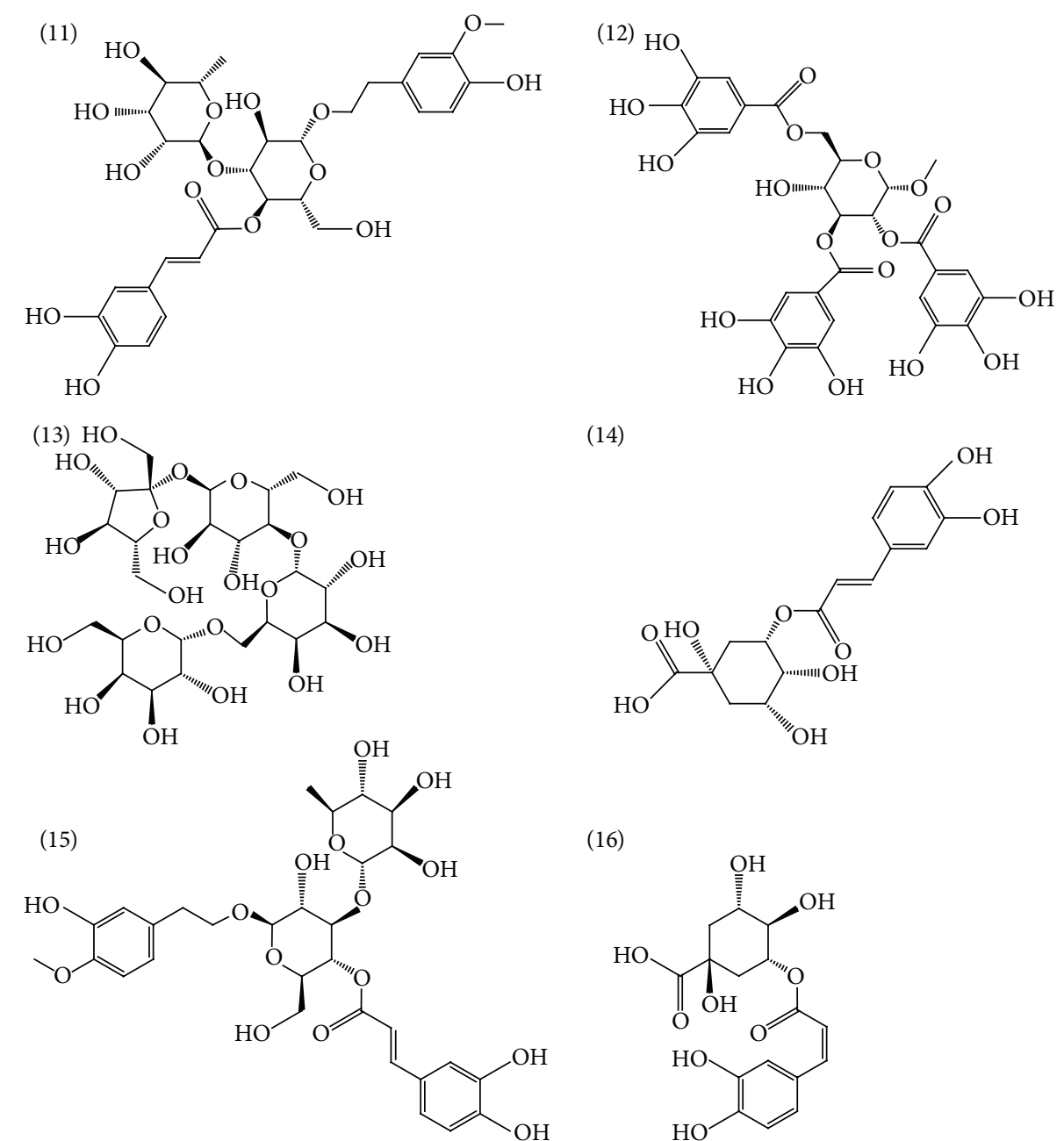

(16)

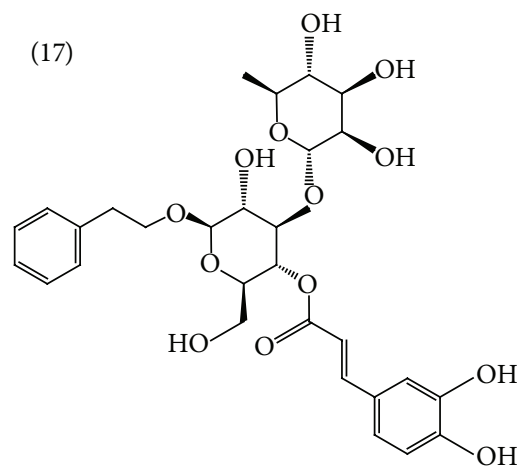<smiles>C[C@H]1O[C@H](OC[C@H]2O[C@@H](Oc3c(-c4ccc(O)c(O)c4)oc4cc(O)cc(O)c4c3=O)[C@@H](O)[C@H](O)[C@H]2O)C(O)[C@@H](O)[C@H]1O</smiles><smiles>[X][M]Cc1ccc(C(=O)N[C@@H](CCC(=O)O)C(=O)O)cc1</smiles><smiles></smiles>

(b)

Figure 4: (a)-(b) The chemical scaffolds of MTX, MTX-PGs, and TCM candidates for acute lymphoblastic leukemia treatment. 


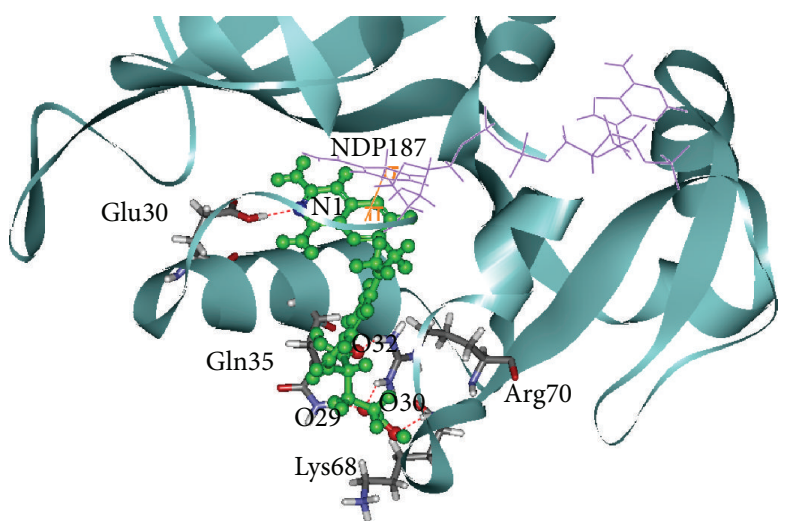

(a)

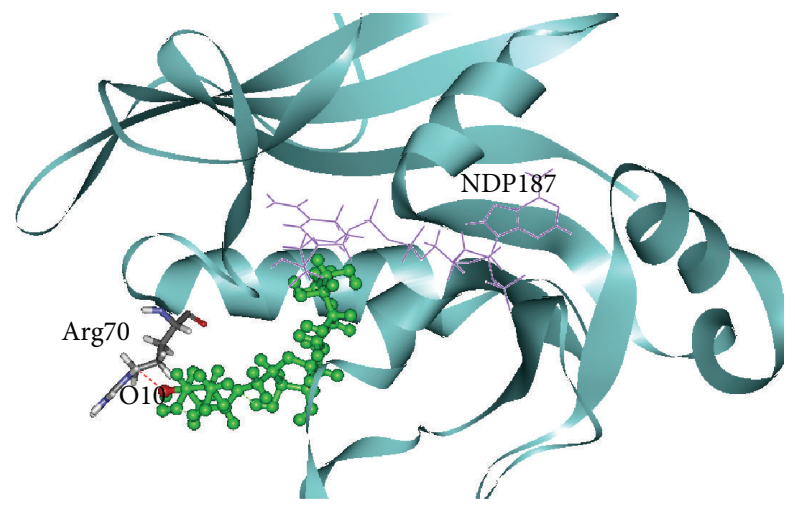

(c)

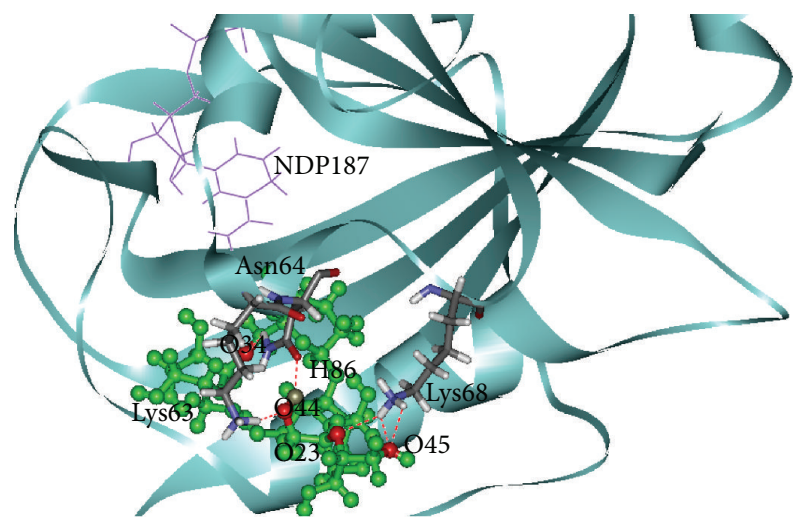

(e)

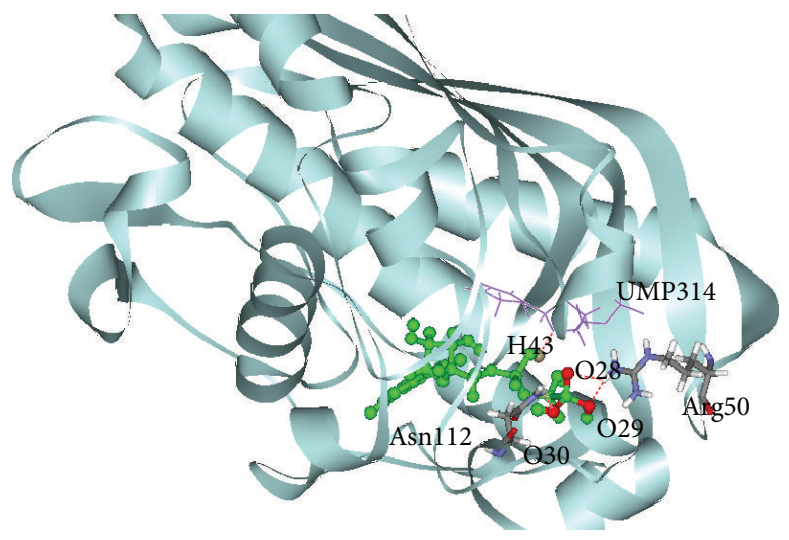

(g)

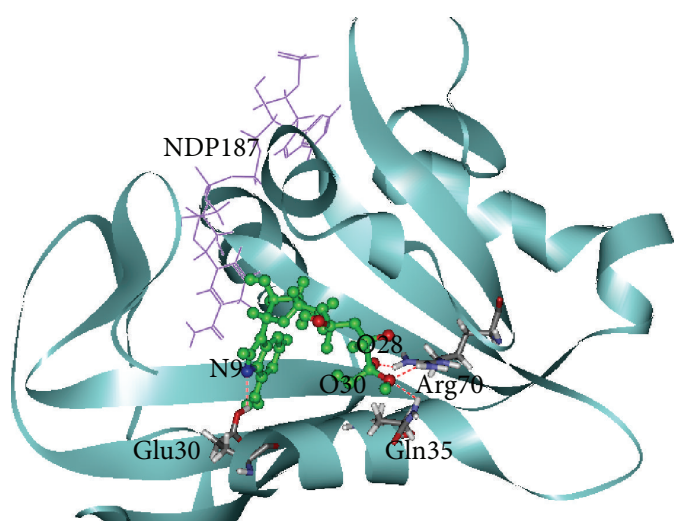

(b)

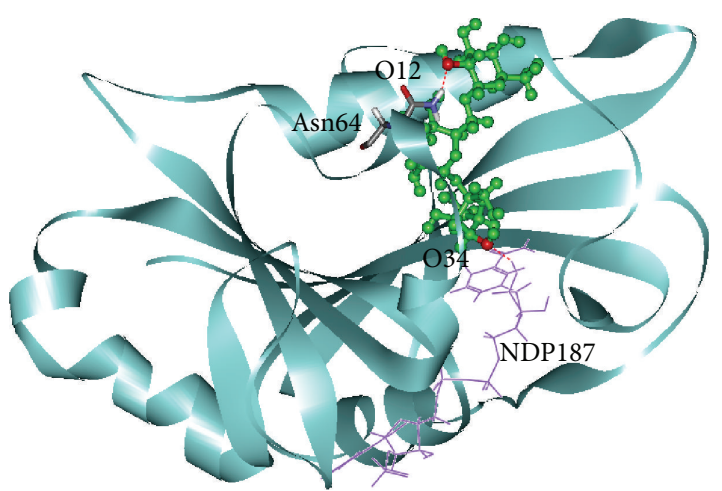

(d)

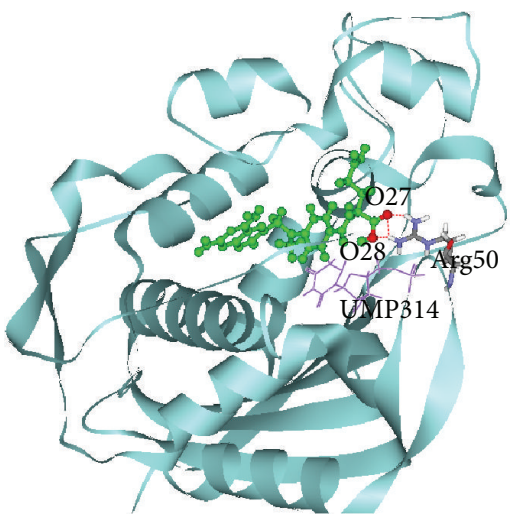

(f)

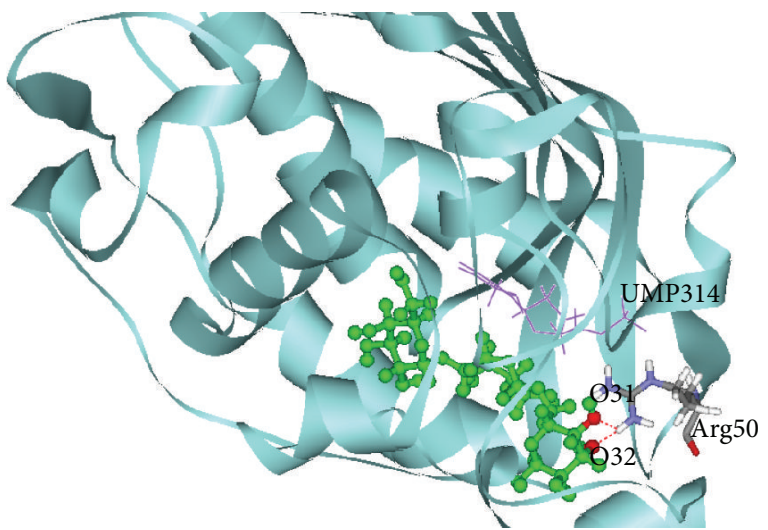

(h)

Figure 5: Continued. 


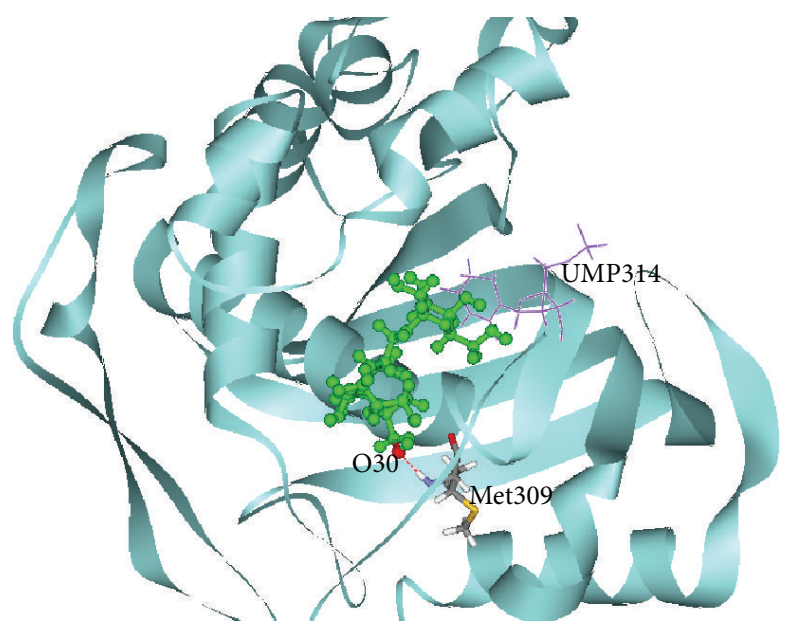

(i)

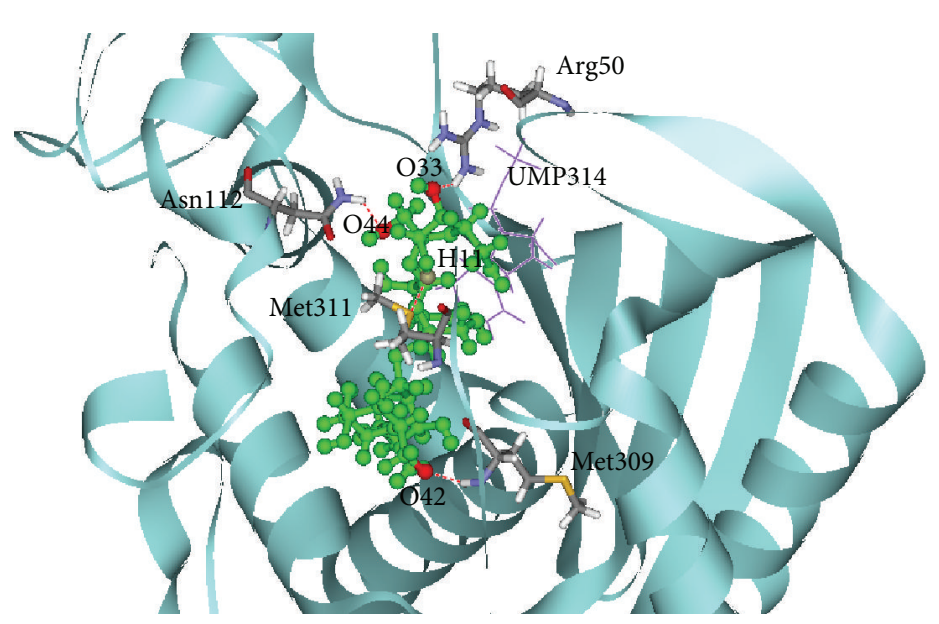

(j)

FIGURE 5: Docking pose of MTX and TCM candidates with DHFR for (a), (b), (c), (d), and (e). Docking pose of MTX-PGs with TS for (f), (g), (h), (i), and (j). TCM candidates are shown in cyan. The cofactors are shown in purple. In H-bond interactions, nitrogen atoms are shown in blue, hydrogen atoms are shown in gray, oxygen atoms are shown in magenta, hydrogen bonds are shown in red dotted line, pi bonds are shown in orange solid line. (a) MTX, (b) and (g) adenosine triphosphate, (c) and (h) manninotriose, (d) and (i) raffinose, (e) and (j) stachyose, and (f) MTX-PGs.

The square correlation coefficients $\left(R^{2}\right)$ between predicted and actual pIC50 of the training set were used to verify accuracy of the model. This building model was applied to predict the pIC50 values of the TCM candidates.

2.3. 3D-Quantitative Structure Activity Relationship (3DQSAR) Models. Comparative molecular field analysis (CoMFA) and comparative molecular similarity indices analysis (CoMSIA) were performed by Sybyl-X 1.1.1 (Tripos Inc., St. Louis, MO, USA) for DHFR inhibitors. LennardJones potential and Coulomb potential were employed to calculate steric and electrostatic interaction energies. The two 3D-QSAR models were further evaluated by crossvalidated correlation coefficient $\left(q^{2}\right)$ and non-cross-validated correlation coefficient $\left(r^{2}\right)$. The correlation between the force field and biological activities was calculated by partial least squares (PLSs) method.

The flowchart for the entire experimental procedure for TCM candidates screening is illustrated in Figure 3.

\section{Results and Discussion}

3.1. Virtual Screening. The virtual screening was performed by the LigandFit Module of DS 2.5 in force field of CHARMm. The receptor binding sites were defined by the binding position of MTX on DHFR protein and by the binding position of MTX-PGs on TS protein. The compounds from our library were docked into the two receptors. In this protocol, the receptors were fixed, and the ligands that complement the binding sites were flexible in energy minimization process. The control compound used in this study was MTX which contains aromatic and heterocyclic rings (Figure 4).
The top eighteen results from DHFR docking score are tabulated in Table 2. The TS docking score for the eighteen candidates are also tabulated in Table 2. All the eighteen TCM candidates had higher Dock Scores than the control methotrexate (MTX) and MTX-PGs. Chemical scaffolds of MTX, MTX-PGs, and the eighteen TCM candidates are shown in Figure 4. Adsorption, solubility, hepatotoxicity, and plasma protein binding were assessed to evaluate pharmacokinetic properties of the selected candidates (Table 3). Considering the factor of hepatotoxicity, we selected the TCM compounds adenosine triphosphate, manninotriose, raffinose, and stachyose for advanced study. MTX and TCM candidates had very poor absorption for human intestine. Binding strength of the ligands to carrier proteins in the blood stream is indicated by the plasma protein binding (PPB) value [21]. MTX has more than $90 \%$ for PPB but adenosine triphosphate, manninotriose, raffinose, and stachyose were less than $90 \%$ for PPB.

Ligand-receptor interactions during docking are shown in Figures 5 and 6. MTX docked on DHFR (Figure 5(a)) through four hydrogen bondings of Glu30, Gln35, Lys68, and Arg70. Adenosne triphosphate formed three H-bonds with Glu30, Gln35, and Arg70 (Figure 5(b)). Manninotriose formed H-bond with Arg28 (Figure 5(c)). Raffinose formed H-bonds with Asn64 and NDP (Figure 5(d)). Stachyose formed H-bonds with Lys63, Asn64, and Lys68 (Figure 5(e)). MTX-PGs docked on TS (Figure 5(f)) by single H-bond with Arg50. Adenosne triphosphate, manninotriose, and stachyose docked on TS (Figures 5(g), 5(h), and 5(j)) by single $\mathrm{H}$-bond with Arg50. Raffinose docked on TS by single $\mathrm{H}$ bond with Met309 (Figure 5(i)). 


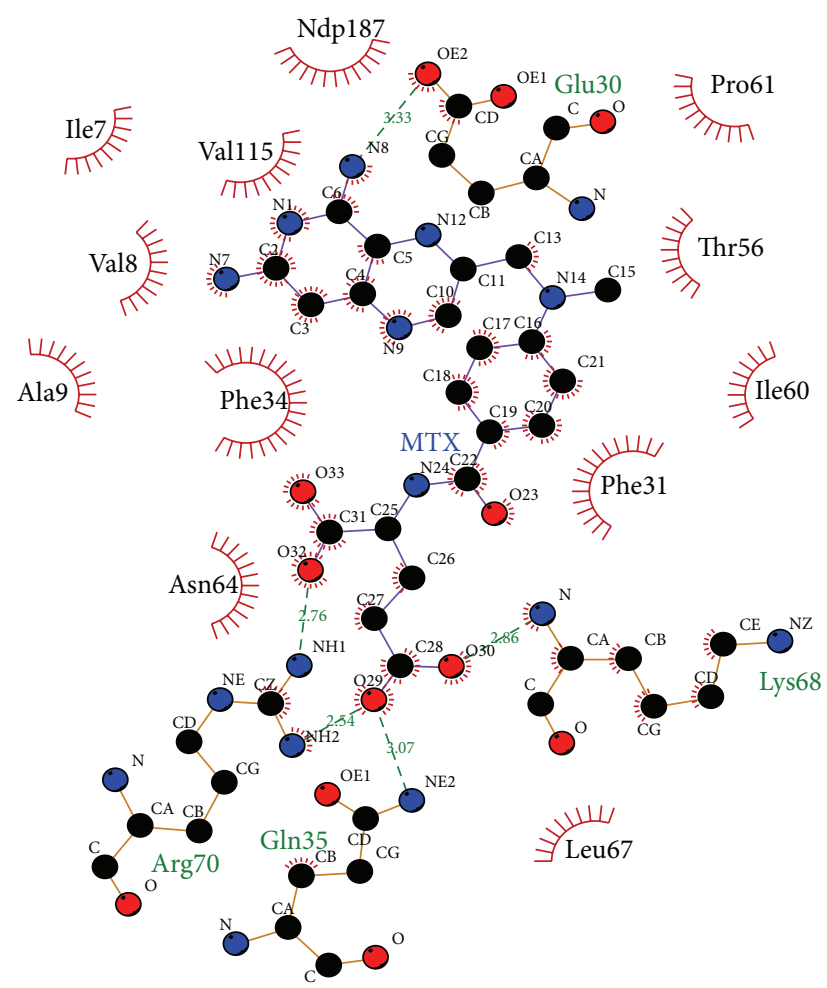

(a)

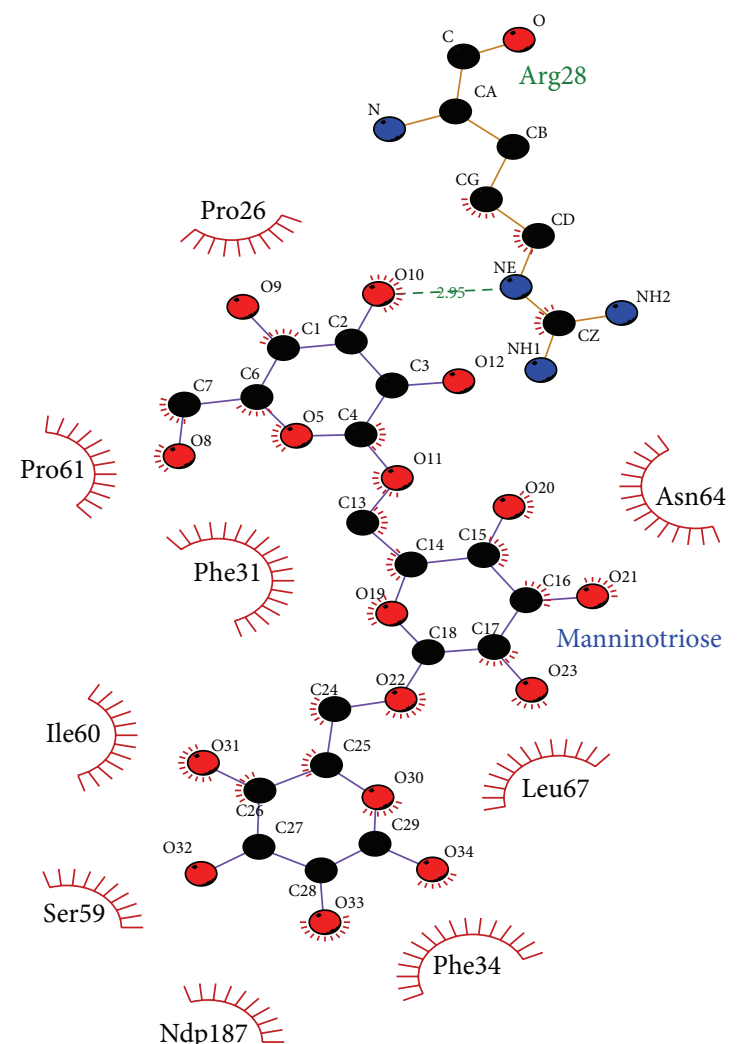

- Ligand bond

- Nonligand bond

9..0 Hydrogen bond and its length
Hiss33 Nonligand residues involved in hydrophobic contact(s) in hydrophobic contact(s)
Corresponding atoms involved

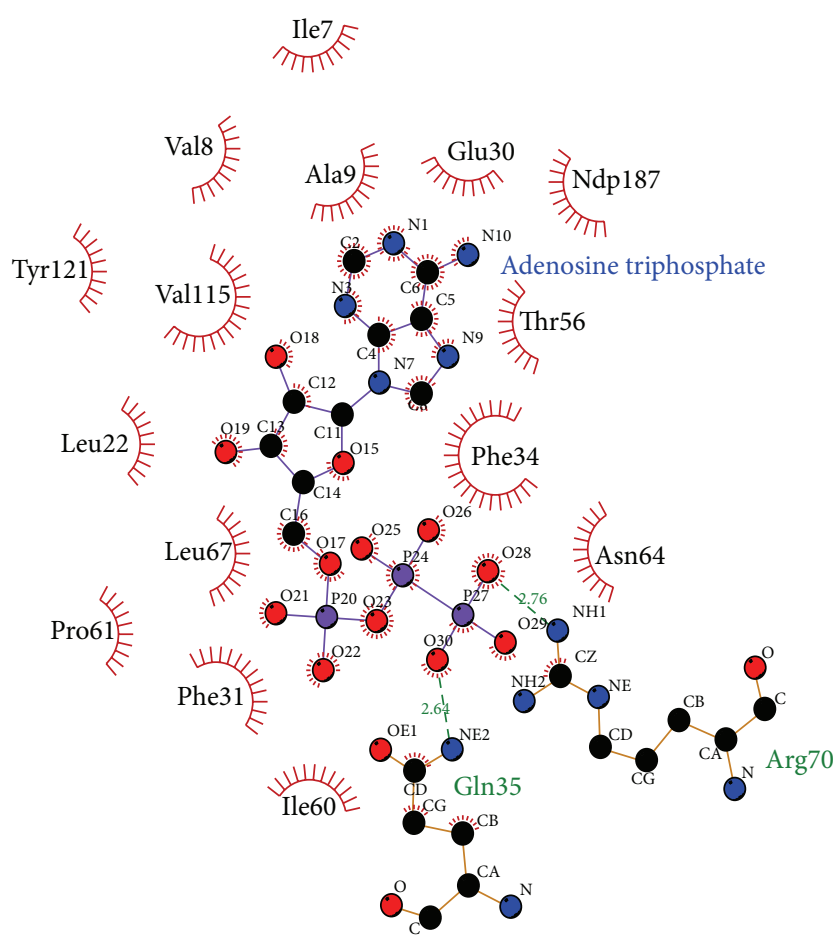

(b)

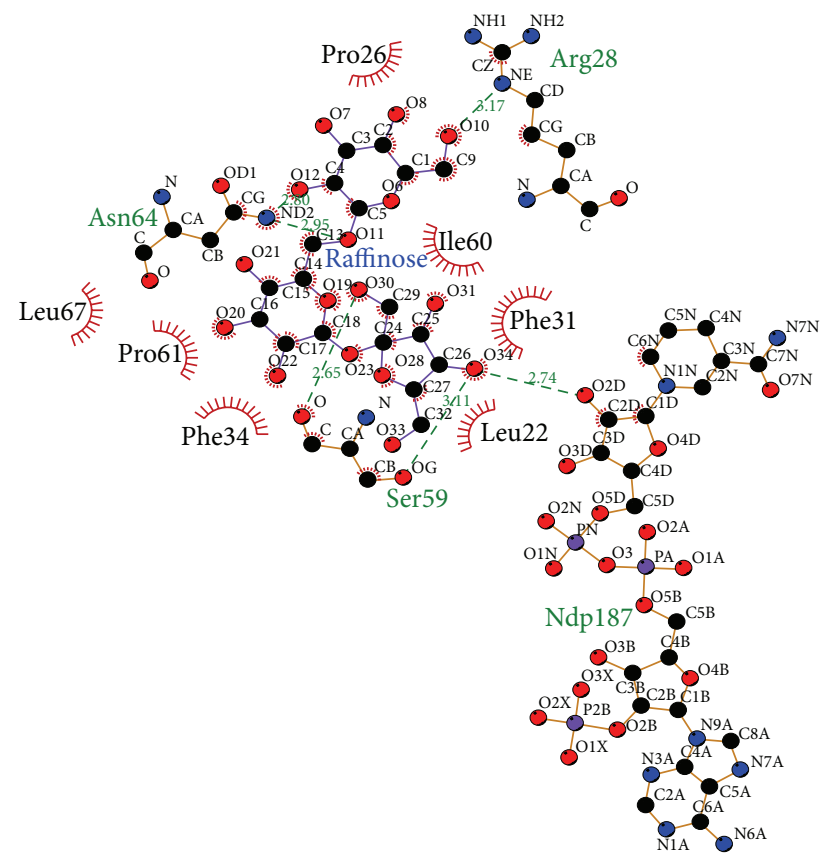
- Ligand bond
- Nonligand bond
3.0. Hydrogen bond and its length

His53 $N$ Nonligand residues involved in hydrophobic contact(s)

o' Corresponding atoms involved in hydrophobic contact(s) (d)

FIgURE 6: Continued. 


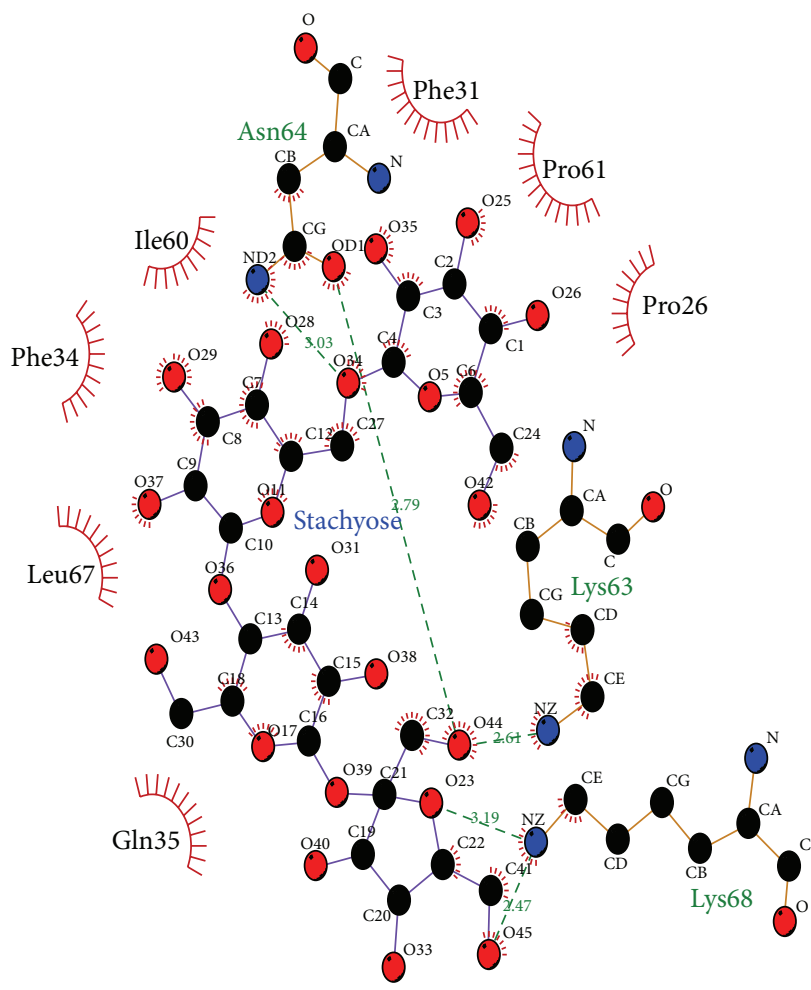

(e)

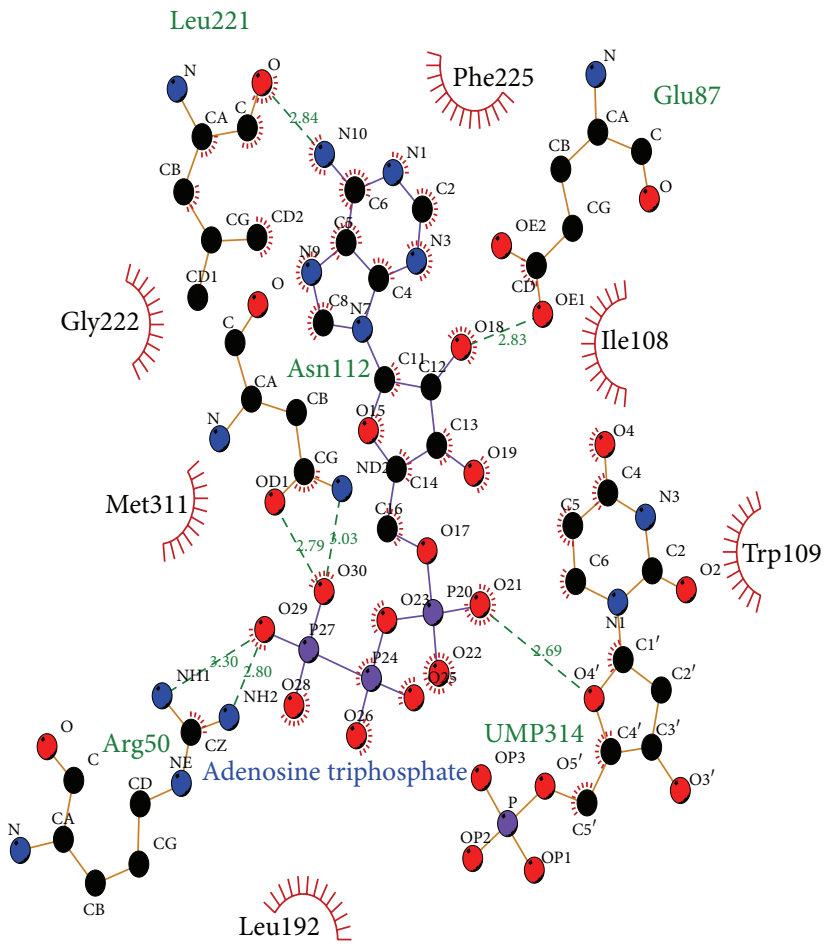

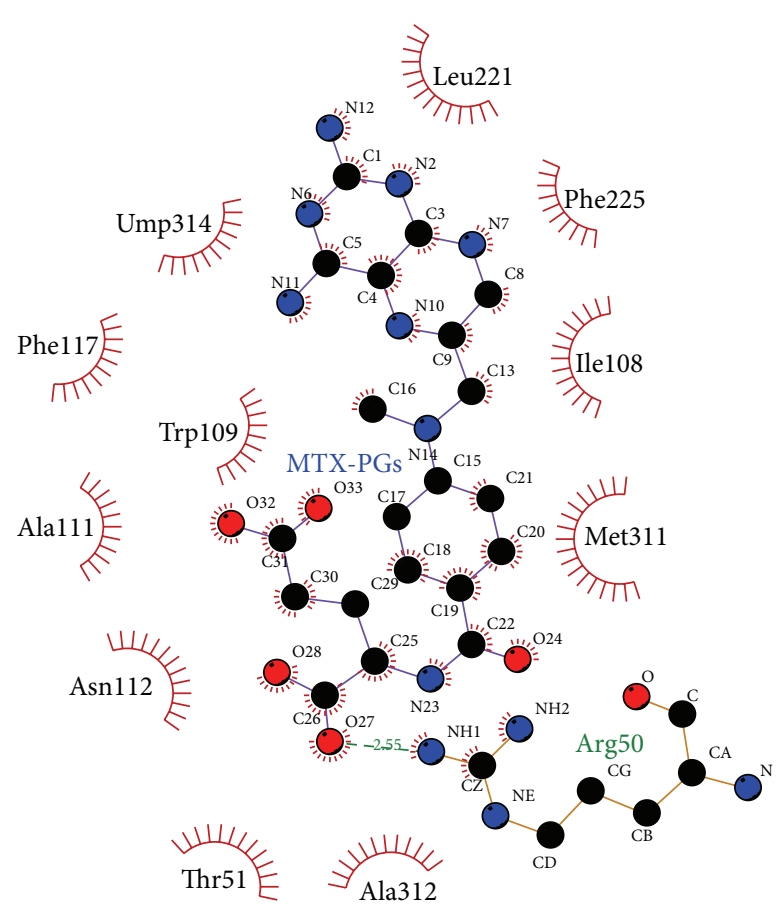

(f)

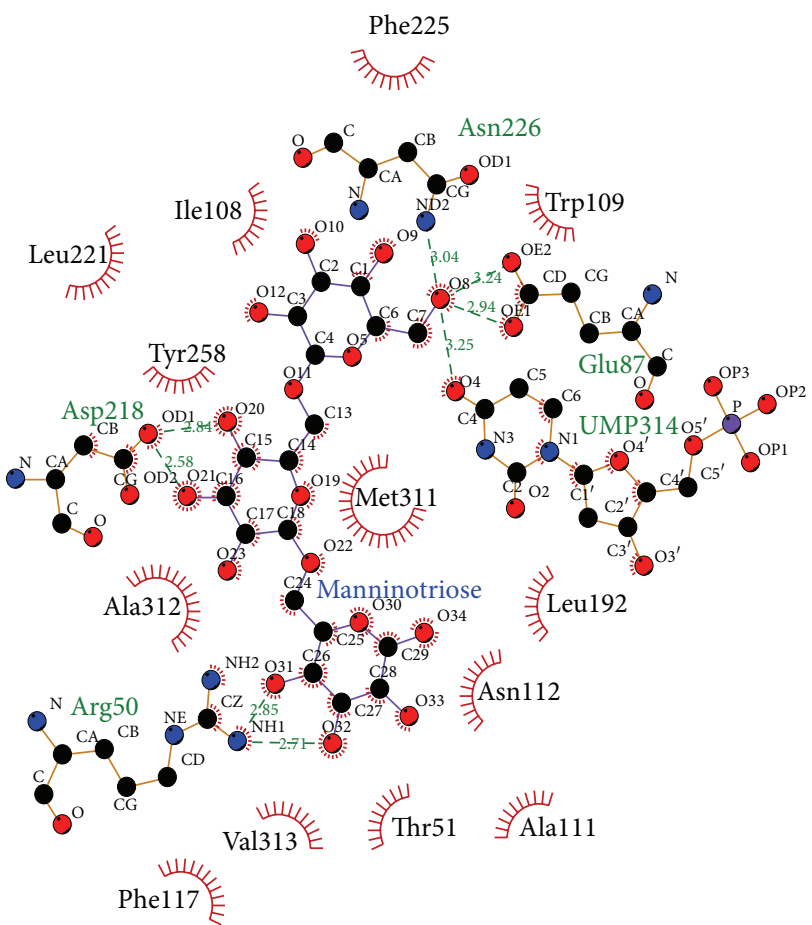
- Ligand bond
Nonligand bond
3.0. Hydrogen bond and its length in hydrophobic conto

" Corresponding atoms involved in hydrophobic contact(s)

His5s Nonligand residues involved in hydrophobic contact(s)

Corresponding atoms involved in hydrophobic contact(s) 


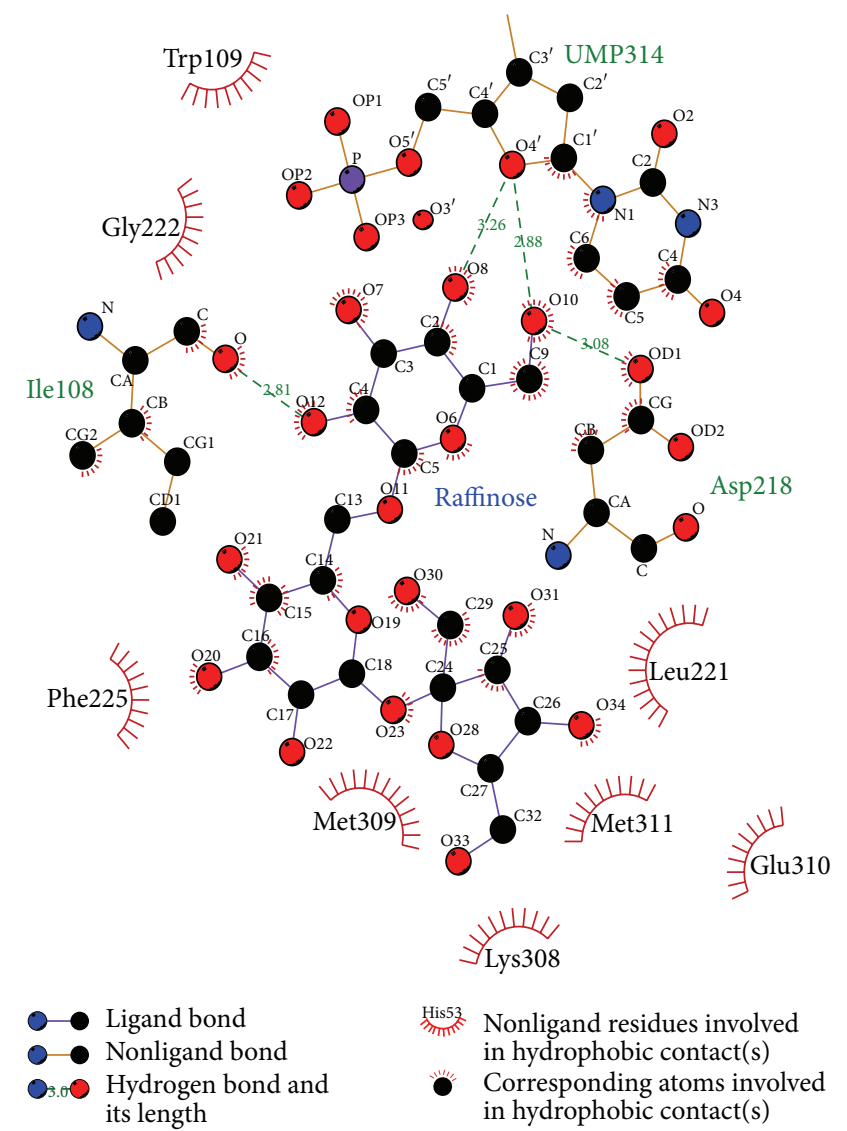

(i)

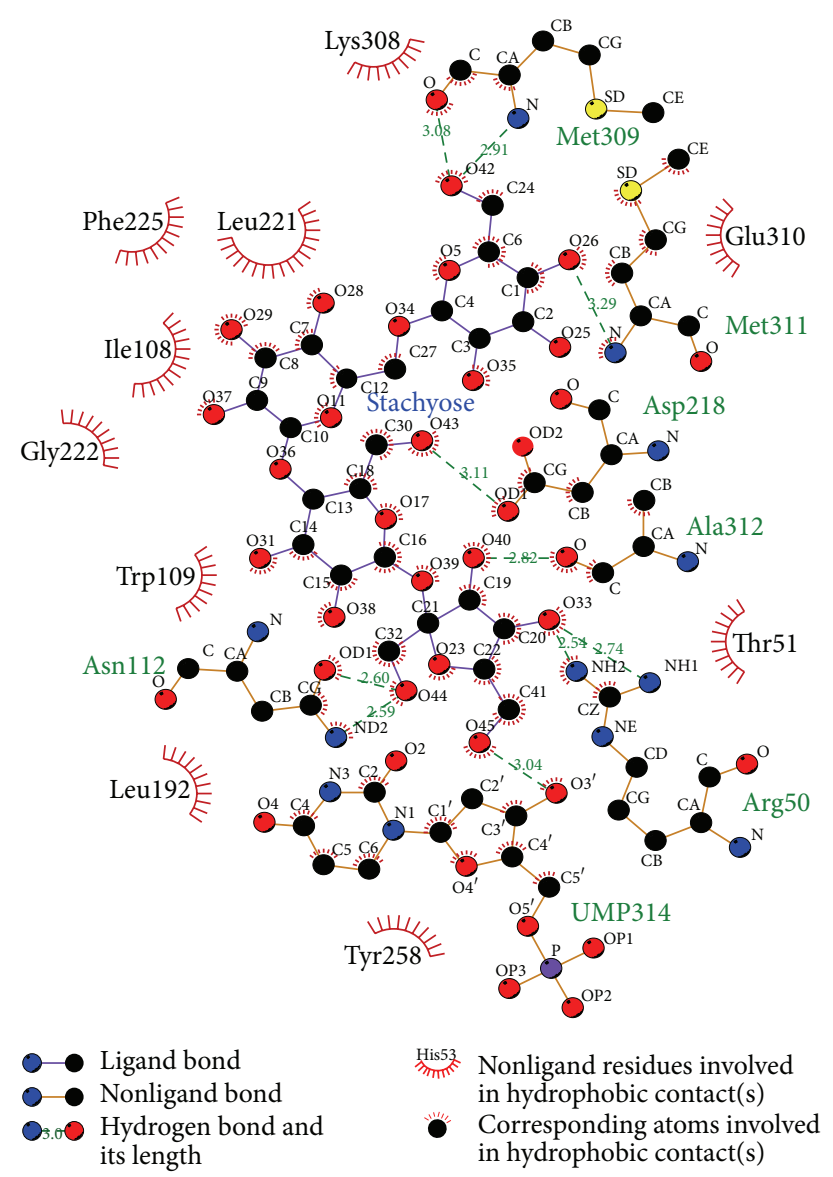

(j)

FIGURE 6: The Ligplot analysis of hydrophobic interactions between DHFR and TCM candidates and between TS and TCM candidates. (a) MTX with DHFR, (b) and (g) adenosine triphosphate with DHFR and TS, (c) and (h) manninotriose with DHFR and TS, (d) and (i) raffinose with DHFR and TS, (e) and (j) stachyose with DHFR and TS, and (f) MTX-PGs with DHFR and TS. Bonds: ligand bonds, nonligand bonds, hydrogen bonds, and hydrophobic are shown in purple, orange, olive green, and brick red, respectively. Atoms: nitrogen, oxygen, carbon, and sulfur are shown in blue, red, black, and yellow, respectively.

Analysis of hydrophobic interactions showed that MTX docking on DHFR was more stable than the TCM candidates. Comparing with chemical structures of the TCM candidates, it could be attributed to the larger size for MTX docking on DHFR (Figures 6(a), 6(b), 6(c), 6(d), and 6(e)). However, the TCM candidates docking on TS were more stable than MTXPGs due to hydrophobic interactions (Figures 6(f), 6(g), 6(h), 6(i), and 6(j)).

3.2. Bioactivity Prediction Using QSAR Models. QSAR models were constructed using known DHFR inhibitors [40] and applied for predicting molecular properties of the TCM ligands. Molecular descriptors associated with bioactivity including BD_Count, Num_RotatableBonds, CHI_V_1, IAC_Mean, JX, JY, SC_3_C, Jurs_FNSA_1, Jurs_RPCS, Jurs SASA, and Shadow_Xlength were used to construct MLR model, SVM model, and Bayesian network model.
Our MLR model was as follows.

GFATempModel_1 $=31.623+2.5173 *$ HBD_Count $0.47471 *$ Num_RotatableBonds $-1.7664 *$ CHI_V_1 12.997 * IAC_Mean - 45.669* JX + 36.62 * JY + $0.11612 *$ SC_3_C + $18.941 *$ Jurs_FNSA_1 $-4.8012 *$ Jurs_RPCS + $0.029451 *$ Jurs_SASA $-0.084377 *$ Shadow_Xlength.

In CoMFA model, the steric fields were the primary contributing factor. In CoMSIA, various factors were considered and modeled. The optimum CoMSIA models were "EHA model" and "EHDA model" based on high $q^{2}$, high $r^{2}$, and low SEE values (Table 4). The "EHA model" was consisting of electrostatic field and hydrophobic and hydrogen bond acceptor. The "EHDA model" was consisting of electrostatic field and hydrophobic and hydrogen bond donor, and hydrogen bond acceptor. The CoMFA model and CoMSIA model of EHDA and of EHA were with ONC of 7, 11, and 12, respectively. 


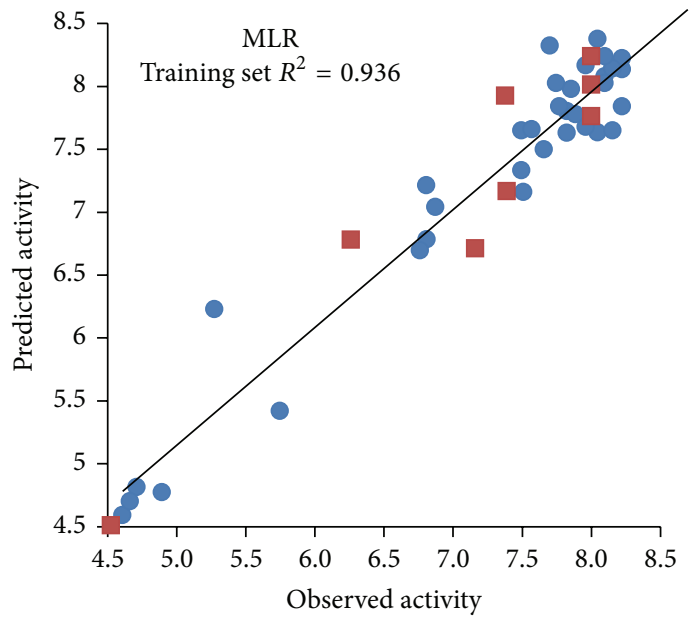

(a)

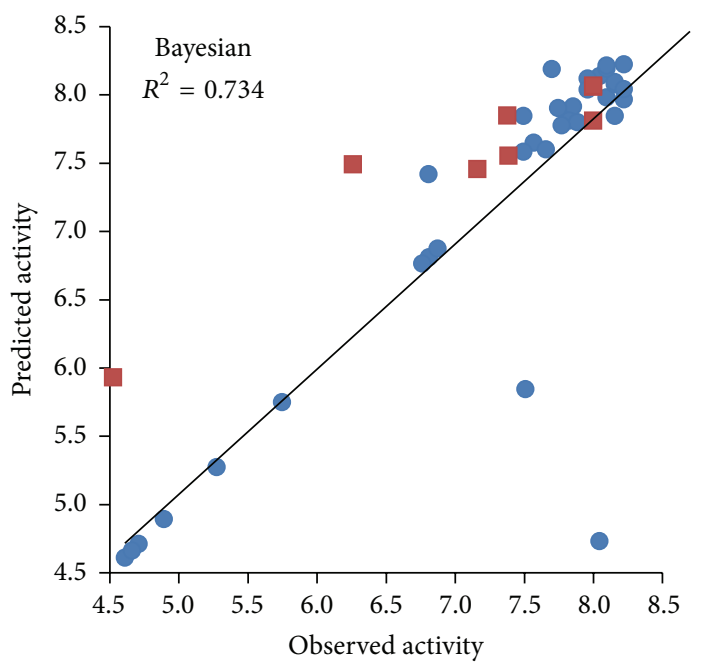

(c)

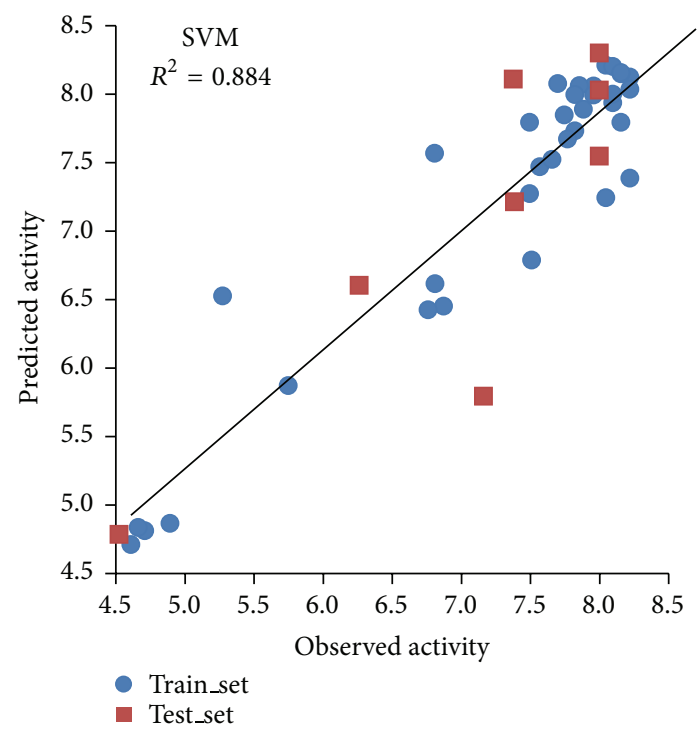

(e)

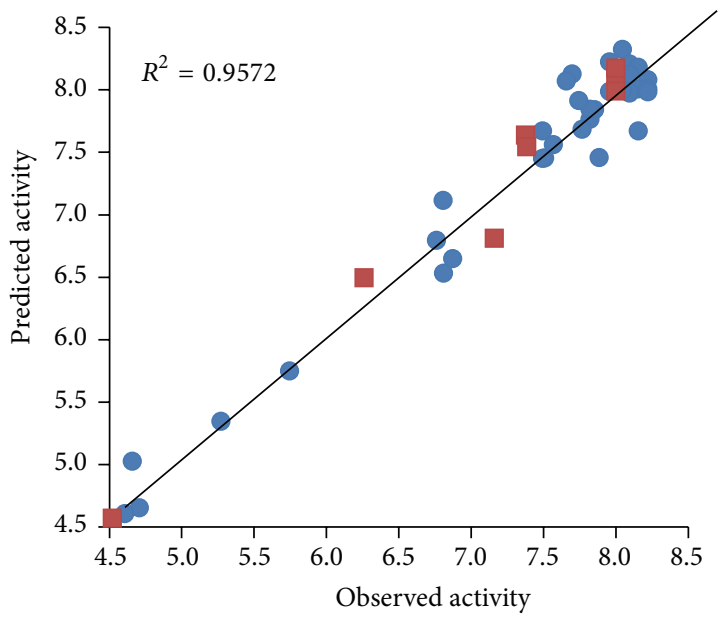

(b)

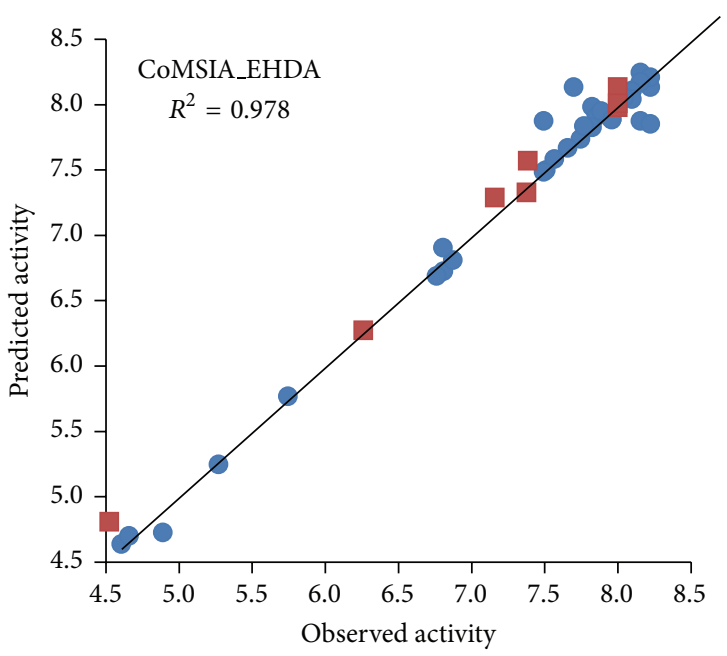

(d)

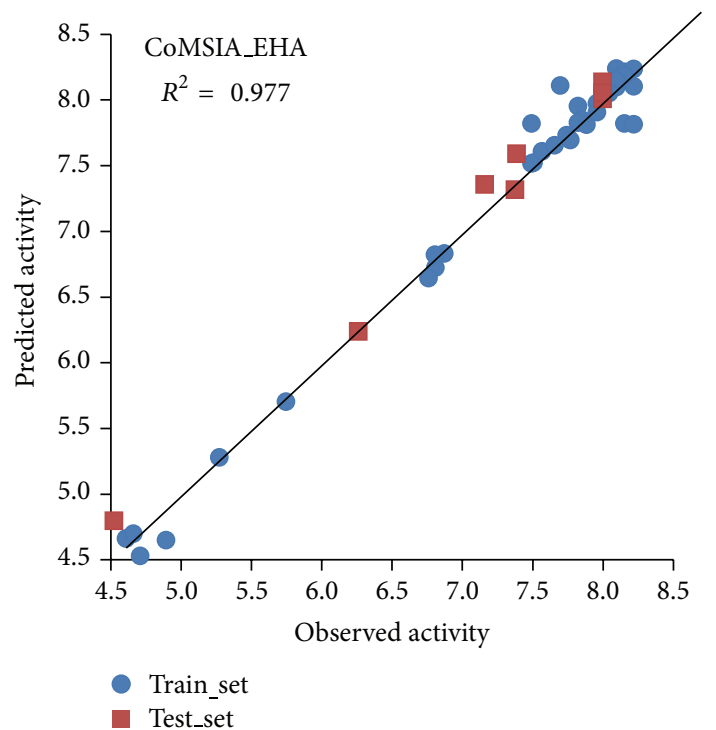

(f)

FIGURE 7: Correlation of observed and predicted activity (pIC50) using 2D-QSAR models and 3D-QSAR models. MLR, Bayesian network, and SVM were 2D-QSAR model. CoMFA, CoMSIA_EHDA, and CoMSIA_EHA were 3D-QSAR model. 


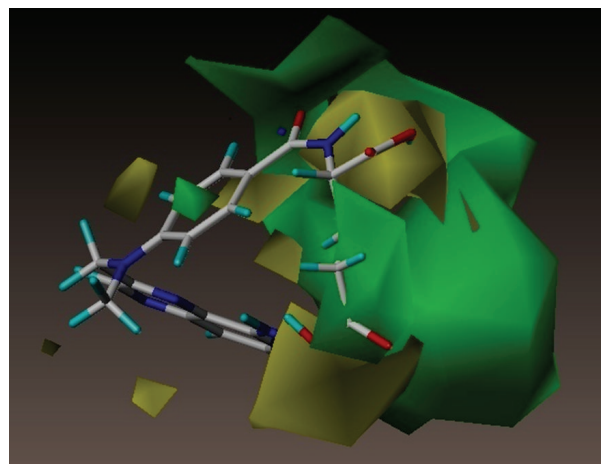

(a)

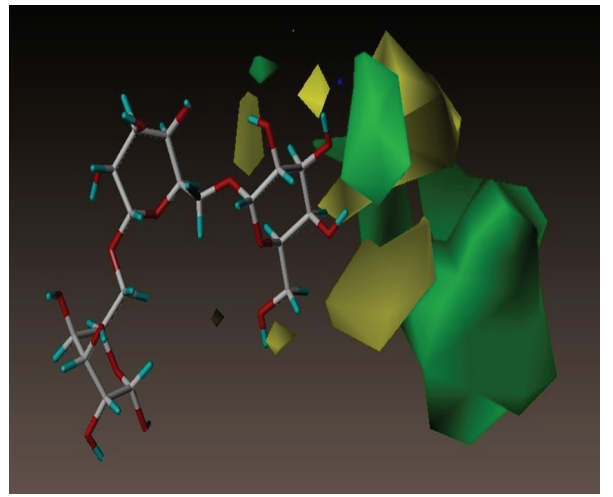

(c)

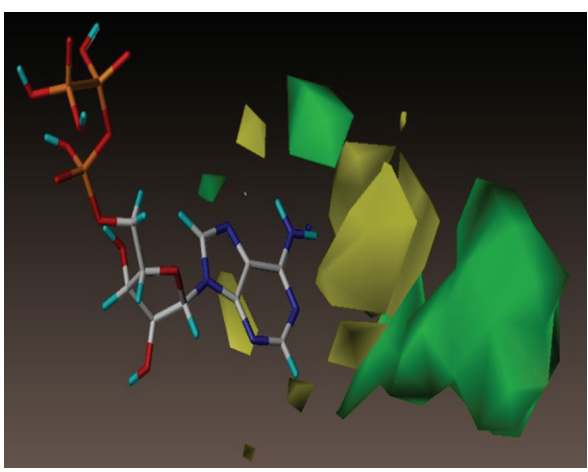

(b)

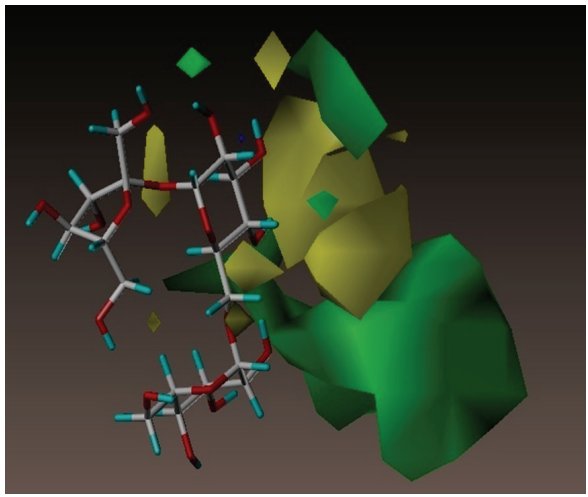

(d)

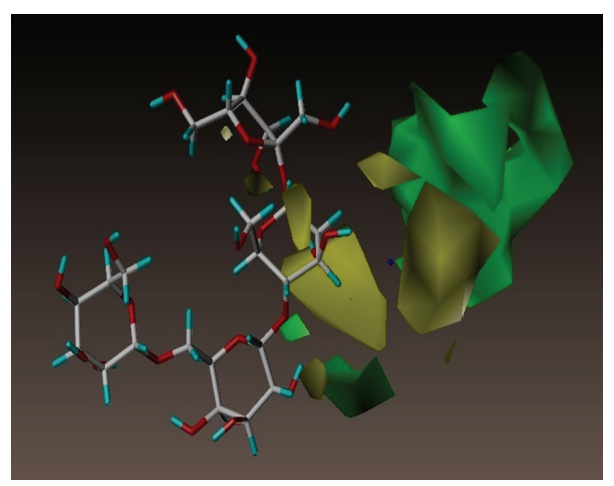

(e)

Figure 8: The CoMFA contour maps for DHFR. (a) MTX, (b) adenosine triphosphate, (c) manninotriose, (d) raffinose, and (e) stachyose. Green and yellow contours denote regions favoring and disfavoring steric fields, respectively. Blue and red contours denote regions favoring and disfavoring electrostatic fields, respectively.

Experimental and predicted pIC50 values of 45 DHFR inhibitors using CoMFA and CoMSIA models are shown in Table 5. Residuals calculated from the differences between observed and predicted pIC50 values ranged between -0.3655 and 0.4311 for the CoMFA, between -0.411 and 0.589 for the CoMSIA with "EHA model," and between -0.431 and 0.569 for CoMSIA with "EHDA model."

The correlations between the predicted and actual bioactivity for DHFR inhibitors are shown in Figure 7. The $R^{2}$ values are 0.936 for MLR, 0.734 for Bayesian network, 0.884 for SVM, 0.957 for CoMFA, 0.977 for CoMSIA with EHA model, and 0.978 for CoMSIA with EHDA model implicate high correlation. High correlation coefficients validated the reliability of the constructed CoMFA and CoMSIA models. The predicted bioactivity values of TCM candidates by $2 \mathrm{D}$ QSAR and 3D-QSAR models are listed in Table 6.

3.3. The Contour Maps of CoMFA and CoMSIA Models. Ligand activities of MTX and the TCM candidates can be 


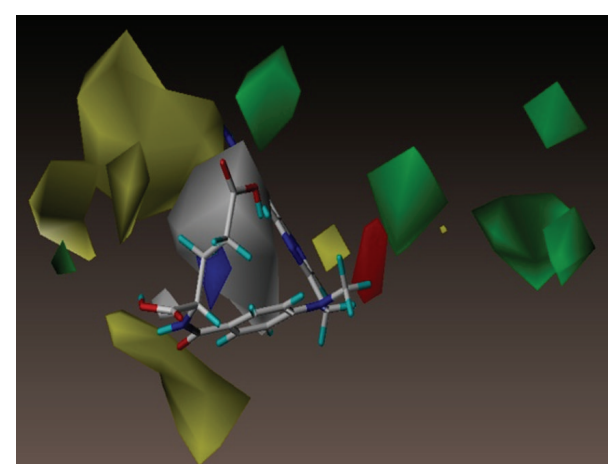

(a)

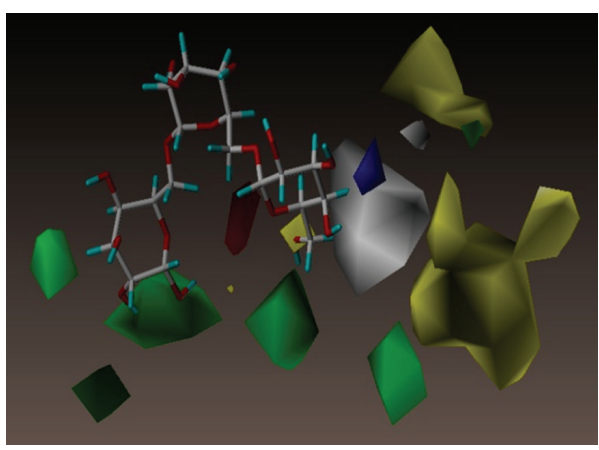

(c)

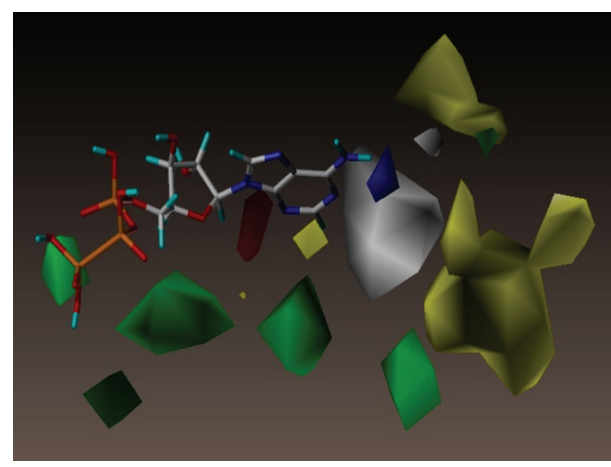

(b)

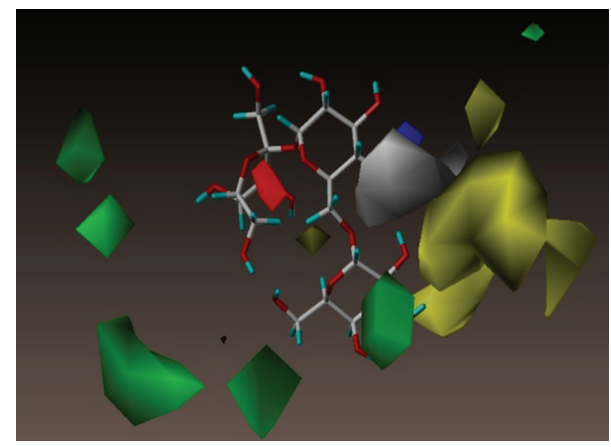

(d)

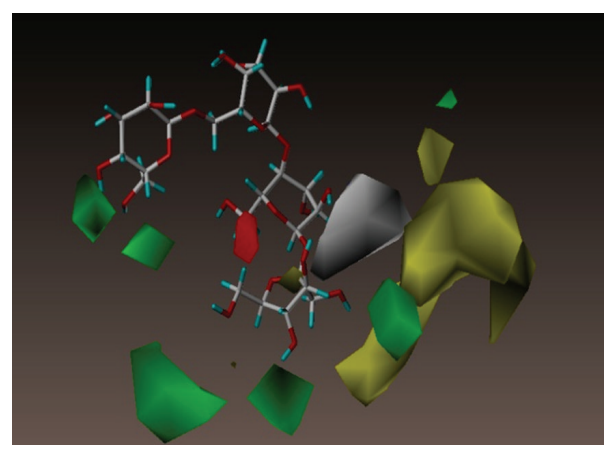

(e)

FIGURE 9: The CoMSIA contour maps of EHA model for DHFR. (a) MTX, (b) adenosine triphosphate, (c) manninotriose, (d) raffinose, and (e) stachyose. Blue and orange contours denote regions favoring and disfavoring electrostatic fields, respectively. Yellow and white contours denote regions favoring and disfavoring hydrophobic fields, respectively. Green and red contours denote regions favoring and disfavoring H-bond acceptor fields, respectively.

predicted based on the 3D-QSAR contour map, including features in steric field, hydrophobic field, and $\mathrm{H}$-bond donor/acceptor characteristics. MTX and the TCM candidates contoured well to the steric features of the CoMFA in Figure 8. CoMSIA map provides more information with regard to bioactivity differences for "EHA model" and "EHDA model" in Figures 9 and 10, respectively. From the consistent results observed among the 3D-QSAR models validations, we inferred that adenosine triphosphate, manninotriose, raffinose, and stachyose of TCM candidates might have good biological activity for DHFR.
Contour to steric favoring and hydrophobic favoring regions was observed for adenosine triphosphate, manninotriose, raffinose, and stachyose. Consistent with the docking pose contour (Figures 8, 9, and 10), we propose that the four TCM candidates may maintain bioactivity for DHFR under dynamic conditions in physiological environments.

\section{Conclusion}

DHFR and TS proteins are key regulators in de novo synthesis of purines and thymidylate. Inhibiton of these proteins has the potential for treating acute lymphoblastic leukemia. 


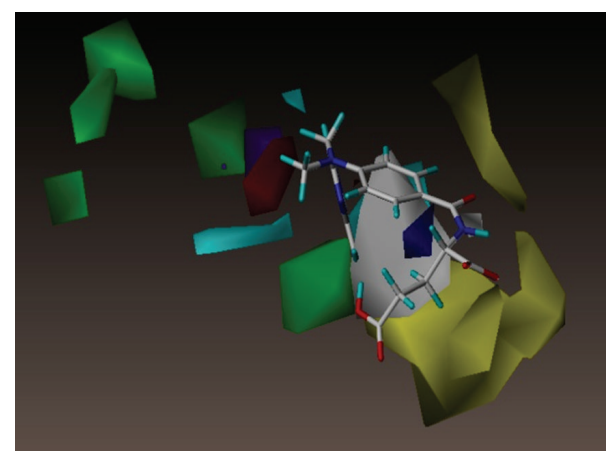

(a)

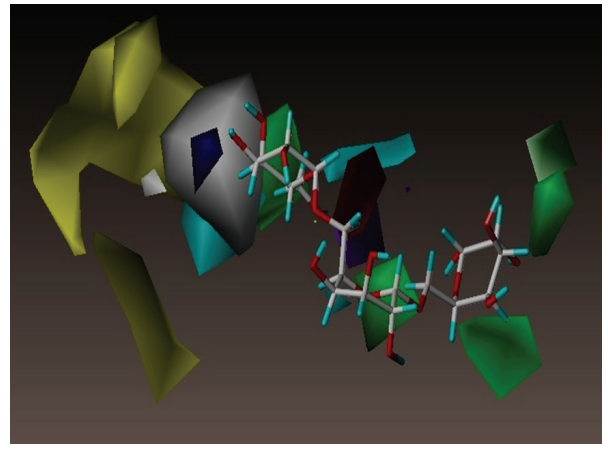

(c)

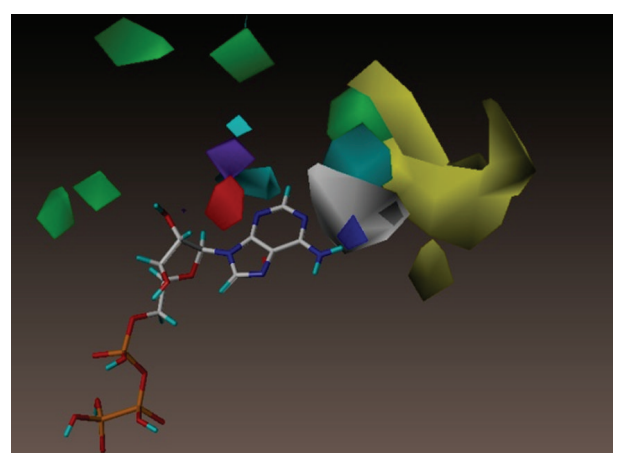

(b)

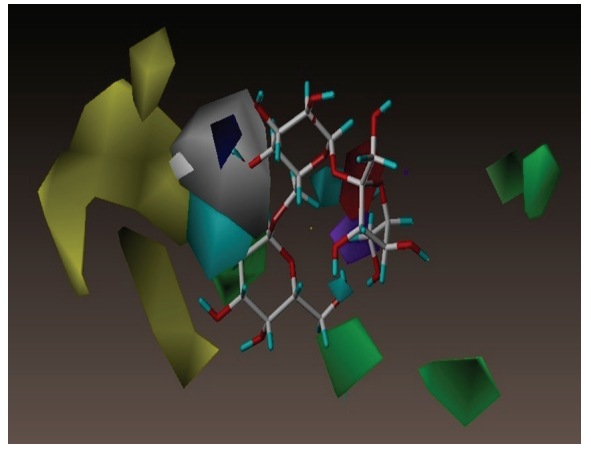

(d)

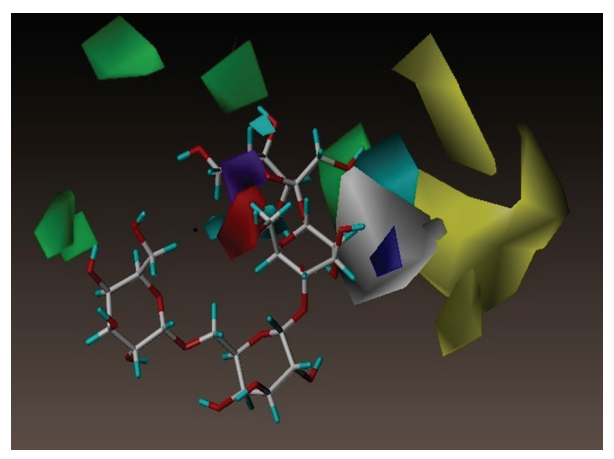

(e)

FIGURE 10: The CoMSIA contour maps of EHDA model for DHFR. (a) MTX, (b) adenosine triphosphate, (c) manninotriose, (d) raffinose, and (e) stachyose. Blue and orange contours denote regions favoring and disfavoring electrostatic fields, respectively. Yellow and white contours denote regions favoring and disfavoring hydrophobic fields, respectively. Green and red contours denote regions favoring and disfavoring $\mathrm{H}$-bond acceptor fields, respectively. Cyan and purple contours denote regions favoring and disfavoring $\mathrm{H}$-bond donor fields, respectively.

In this study, we applied virtual screen and QSAR models based on structure-based and ligand-based methods in order to identify the potential TCM compounds. The TCM compounds adenosine triphosphate, manninotriose, raffinose, and stachyose could bind on DHFR and TS specifically and had low hepatotoxicity. These TCM compounds had potential to improve the side effects of MTX for ALL treatment.

\section{Conflict of Interests}

The authors declare that they have no conflict of interests regarding the publication of this paper.

\section{Acknowledgments}

The research was supported by Grants from the National Science Council of Taiwan (NSC102-2632-E-468-001-MY3, NSC102-2325-B039-001, and NSC102-2221-E-468-027-), Asia University (101-ASIA-24, 101-ASIA-59, ASIA100-CMU-2, and ASIA101-CMU-2), and China Medical University Hospital (DMR-103-001, DMR-103-058, and DMR-103-096). This study is also supported in part by Taiwan Department of Health Clinical Trial and Research Center of Excellence (DOH102-TD-B-111-004) and Taiwan Department of Health Cancer Research Center of Excellence 
(MOHW103-TD-B-111-03), and CMU under the Aim for Top University Plan of the Ministry of Education, Taiwan.

\section{References}

[1] L. H. Hartwell and M. B. Kastan, "Cell cycle control and cancer," Science, vol. 266, no. 5192, pp. 1821-1828, 1994.

[2] M. J. Chen, T. Shimada, and A. D. Moulton, "The functional human dihydrofolate reductase gene," Journal of Biological Chemistry, vol. 259, no. 6, pp. 3933-3943, 1984.

[3] Y. C. Hsieh, P. Tedeschi, R. A. Lawal et al., "Enhanced degradation of dihydrofolate reductase through inhibition of NAD kinase by nicotinamide analogs," Molecular Pharmacology, vol. 83, no. 2, pp. 339-353, 2013.

[4] M. Krajinovic and A. Moghrabi, "Pharmacogenetics of methotrexate," Pharmacogenomics, vol. 5, no. 7, pp. 819-834, 2004.

[5] G. Toffoli, A. Russo, F. Innocenti et al., "Effect of methylenetetrahydrofolate reductase $677 \mathrm{C} \rightarrow \mathrm{T}$ polymorphism on toxicity and homocysteine plasma level after chronic methotrexate treatment of ovarian cancer patients," International Journal of Cancer, vol. 103, no. 3, pp. 294-299, 2003.

[6] A. Patiño-García, M. Zalacaín, L. Marrodán, M. San-Julián, and L. Sierrasesúmaga, "Methotrexate in pediatric osteosarcoma: response and toxicity in relation to genetic polymorphisms and dihydrofolate reductase and reduced folate carrier 1 expression," Journal of Pediatrics, vol. 154, no. 5, pp. 688-693, 2009.

[7] P. Ranganathan, "An update on methotrexate pharmacogenetics in rheumatoid arthritis," Pharmacogenomics, vol. 9, no. 4, pp. 439-451, 2008.

[8] E. Campalani, M. Arenas, A. M. Marinaki, C. M. Lewis, J. N. W. N. Barker, and C. H. Smith, "Polymorphisms in folate, pyrimidine, and purine metabolism are associated with efficacy and toxicity of methotrexate in psoriasis," Journal of Investigative Dermatology, vol. 127, no. 8, pp. 1860-1867, 2007.

[9] K. R. Herrlinger, J. R. F. Cummings, M. C. N. M. Barnardo, M. Schwab, T. Ahmad, and D. P. Jewell, "The pharmacogenetics of methotrexate in inflammatory bowel disease," Pharmacogenetics and Genomics, vol. 15, no. 10, pp. 705-711, 2005.

[10] C. M. Ulrich, Y. Yasui, R. Storb et al., "Pharmacogenetics of methotrexate: toxicity among marrow transplantation patients varies with the methylenetetrahydrofolate reductase C677T polymorphism," Blood, vol. 98, no. 1, pp. 231-234, 2001.

[11] T. S. Mikkelsen, C. F. Thorn, J. J. Yang et al., "PharmGKB summary: methotrexate pathway," Pharmacogenetics and Genomics, vol. 21, no. 10, pp. 679-686, 2011.

[12] J. C. Barredo, T. W. Synold, J. Laver et al., "Differences in constitutive and post-methotrexate folylpolyglutamate synthetase activity in B-lineage and T-lineage leukemia," Blood, vol. 84, no. 2, pp. 564-569, 1994.

[13] L. Huang, W. J. E. Tissing, R. de Jonge, B. D. van Zelst, and R. Pieters, "Polymorphisms in folate-related genes: association with side effects of high-dose methotrexate in childhood acute lymphoblastic leukemia," Leukemia, vol. 22, no. 9, pp. 17981800, 2008.

[14] R. Gorlick, E. Goker, T. Trippett et al., "Intrinsic and acquired resistance to methotrexate in acute leukemia," New England Journal of Medicine, vol. 335, no. 14, pp. 1041-1048, 1996.

[15] B. A. Chabner, C. J. Allegra, and G. A. Curt, "Polyglutamation of methotrexate: is Methotrexate a prodrug?" Journal of Clinical Investigation, vol. 76, no. 3, pp. 907-912, 1985.
[16] K. Schmiegelow, "Advances in individual prediction of methotrexate toxicity: a review," British Journal of Haematology, vol. 146, no. 5, pp. 489-503, 2009.

[17] S. A. Jacobs, R. H. Adamson, and B. A. Chabner, "Stoichiometric inhibition of mammalian dihydrofolate reductase by the $\gamma$ glutamyl metabolite of methotrexate, 4 amino 4 deoxy N10 methylpteroylglutamyl $\gamma$ glutamate," Biochemical and Biophysical Research Communications, vol. 63, no. 3, pp. 692-698, 1975.

[18] A. K. Fotoohi and F. Albertioni, "Mechanisms of antifolate resistance and methotrexate efficacy in leukemia cells," Leukemia and Lymphoma, vol. 49, no. 3, pp. 410-426, 2008.

[19] J. C. White and I. D. Goldman, "Mechanism of action of methotrexate. IV. Free intracellular methotrexate required to suppress dihydrofolate reduction to tetrahydrofolate by Ehrlich ascites tumor cells in vitro," Molecular Pharmacology, vol. 12, no. 5, pp. 711-719, 1976.

[20] C. M. Baugh, C. L. Krumdieck, and M. G. Nair, "Polygammaglutamyl metabolites of methotrexate," Biochemical and Biophysical Research Communications, vol. 52, no. 1, pp. 27-34, 1973.

[21] I. C. Hung, S. S. Chang, P. C. Chang, C. C. Lee, and C. Y. C. Chen, "Memory enhancement by traditional Chinese medicine?" Journal of Biomolecular Structure \& Dynamics, vol. 31, no. 12, pp. 1411-1439, 2013.

[22] S. Kishi, J. Griener, C. Cheng et al., "Homocysteine, pharmacogenetics, and neurotoxicity in children with leukemia," Journal of Clinical Oncology, vol. 21, no. 16, pp. 3084-3091, 2003.

[23] D. H. Mahoney Jr., J. J. Shuster, R. Nitschke et al., "Acute neurotoxicity in children with B-precursor acute lymphoid leukemia: an association with intermediate-dose intravenous methotrexate and intrathecal triple therapy-a pediatric oncology group study," Journal of Clinical Oncology, vol. 16, no. 5, pp. $1712-1722,1998$.

[24] G. Österlundh, I. Kjellmer, B. Lannering, L. Rosengren, U. A. Nilsson, and I. Márky, "Neurochemical markers of brain damage in cerebrospinal fluid during induction treatment of acute lymphoblastic leukemia in children," Pediatric Blood and Cancer, vol. 50, no. 4, pp. 793-798, 2008.

[25] A. Shuper, B. Stark, L. Kornreich, I. J. Cohen, G. Avrahami, and I. Yaniv, "Methotrexate-related neurotoxicity in the treatment of childhood acute lymphoblastic leukemia," The Israel Medical Association Journal, vol. 4, no. 11, pp. 1050-1053, 2002.

[26] I. Costea, A. Moghrabi, C. Laverdiere, A. Graziani, and M. Krajinovic, "Folate cycle gene variants and chemotherapy toxicity in pediatric patients with acute lymphoblastic leukemia," Haematologica, vol. 91, no. 8, pp. 1113-1116, 2006.

[27] R. C. Choudhury, S. K. Ghosh, and A. K. Palo, "Cytogenetic toxicity of methotrexate in mouse bone marrow," Environmental Toxicology and Pharmacology, vol. 8, no. 3, pp. 191-196, 2000.

[28] L. R. Belur, R. I. James, C. May et al., "Methotrexate preconditioning allows sufficient engraftment to confer drug resistance in mice transplanted with marrow expressing drug-resistant dihydrofolate reductase activity," Journal of Pharmacology and Experimental Therapeutics, vol. 314, no. 2, pp. 668-674, 2005.

[29] S. L. Whittle and R. A. Hughes, "Folate supplementation and methotrexate treatment in rheumatoid arthritis: a review," Rheumatology, vol. 43, no. 3, pp. 267-271, 2004.

[30] S. Saigal, R. K. Singh, and B. Poddar, "Acute methotrexate toxicity presenting as multiorgan failure and acute pneumonitis: a rare case report," Indian Journal of Critical Care Medicine, vol. 16, no. 4, pp. 225-227, 2012. 
[31] B. C. Widemann and P. C. Adamson, "Understanding and managing methotrexate nephrotoxicity," Oncologist, vol. 11, no. 6, pp. 694-703, 2006.

[32] S. G. Yarlagadda and M. A. Perazella, "Drug-induced crystal nephropathy: an update," Expert Opinion on Drug Safety, vol. 7, no. 2, pp. 147-158, 2008.

[33] P. Halonen, J. Mattila, T. Ruuska, M. K. Salo, and A. Mäkipernaa, "Liver histology after current intensified therapy for childhood acute lymphoblastic leukemia: microvesicular fatty change and siderosis are the main findings," Medical and Pediatric Oncology, vol. 40, no. 3, pp. 148-154, 2003.

[34] T. Dervieux, D. Furst, D. O. Lein et al., "Polyglutamation of methotrexate with common polymorphisms in reduced folate carrier, aminoimidazole carboxamide ribonucleotide transformylase, and thymidylate synthase are associated with methotrexate effects in rheumatoid arthritis," Arthritis and Rheumatism, vol. 50, no. 9, pp. 2766-2774, 2004.

[35] M. L. Becker, R. Gaedigk, L. Van Haandel et al., "The effect of genotype on methotrexate polyglutamate variability in juvenile idiopathic arthritis and association with drug response," Arthritis and Rheumatism, vol. 63, no. 1, pp. 276-285, 2011.

[36] C.-H. Wang, W.-D. Lin, D.-T. Bau et al., "Appearance of acanthosis nigricans may precede obesity: an involvement of the insulin/IGF receptor signaling pathway," BioMedicine, vol. 3, no. 2, pp. 82-87, 2013.

[37] M.-C. Lin, S.-Y. Tsai, F.-Y. Wang et al., "Leptin induces cell invasion and the upregulation of matrilysin in human colon cancer cells," BioMedicine, vol. 3, no. 4, pp. 174-180, 2013.

[38] I. C. Chou, W.-D. Lin, C.-H. Wang et al., "Association analysis between Tourette's syndrome and two dopamine genes (DAT1, DBH) in Taiwanese children," BioMedicine, vol. 3, no. 2, pp. 8891, 2013.

[39] T. Yamamoto, W.-C. Hung, T. Takano, and A. Nishiyama, "Genetic nature and virulence of community-associated methicillin-resistant Staphylococcus aureus," BioMedicine, vol. 3, no. 1, pp. 2-18, 2013.

[40] Y.-M. Chang, B. K. Velmurugan, W. W. Kuo et al., "Inhibitory effect of alpinate Oxyphyllae fructus extracts on Ang IIinduced cardiac pathological remodeling-related pathways in H9c2 cardiomyoblast cells," BioMedicine, vol. 3, no. 4, pp. 148152, 2013.

[41] S. P. Mahamuni, R. D. Khose, F. Menaa, and S. L. Badole, "Therapeutic approaches to drug targets in hyperlipidemia," BioMedicine, vol. 2, no. 4, pp. 137-146, 2012.

[42] Y.-T. Chang, W.-D. Lin, Z.-N. Chin et al., "Nonketotic hyperglycinemia: a case report and brief review," BioMedicine, vol. 2, no. 2, pp. 80-82, 2012.

[43] W.-Y. Lin, H.-P. Liu, J.-S. Chang et al., "Genetic variations within the PSORS1 region affect Kawasaki disease development and coronary artery aneurysm formation," BioMedicine, vol. 3, no. 2, pp. 73-81, 2013.

[44] I. C. Chou, W.-D. Lin, C.-H. Wang et al., "Möbius syndrome in a male with XX/XY mosaicism," BioMedicine, vol. 3, no. 2, pp. 102-104, 2013.

[45] D.-Y. Lin, F.-J. Tsai, C.-H. Tsai, and C.-Y. Huang, "Mechanisms governing the protective effect of $17 \beta$-estradiol and estrogen receptors against cardiomyocyte injury," BioMedicine, vol. 1, no. 1, pp. 21-28, 2011.

[46] C.-H. Wang, W.-D. Lin, and F.-J. Tsai, "Craniofacial dysmorphism, what is your diagnosis?” BioMedicine, vol. 2, no. 2, pp. 49-50, 2012.
[47] C. C. Lee, C.-H. Tsai, L. Wan et al., "Increased incidence of Parkinsonism among Chinese with $\beta$-glucosidase mutation in central Taiwan," BioMedicine3, no. 2, pp. 92-94, 2013.

[48] F.-J. Tsai, "Biomedicine brings the future nearer," BioMedicine, vol. 1, no. 1, p. 1, 2011.

[49] F.-J. Tsai, "Rare diseases: a mysterious puzzle," BioMedicine, vol. 3, no. 2, p. 65, 2013.

[50] Y. A. Tsou, K. C. Chen, S. S. Chang, Y. R. Wen, and C. Y. Chen, "A possible strategy against head and neck cancer: in silico investigation of three-in-one inhibitors," Journal of Biomolecular Structure \& Dynamics, vol. 31, no. 12, pp. 13581369, 2013.

[51] Y. A. Tsou, K. C. Chen, H. C. Lin, S. S. Chang, and C. Y. C. Chen, "Uroporphyrinogen decarboxylase as a potential target for specific components of traditional Chinese Medicine: a virtual screening and molecular dynamics study," PLOS ONE, vol. 7, no. 11, 2012.

[52] S. C. Yang, S. S. Chang, H. Y. Chen, and C. Y. C. Chen, "Identification of Potent EGFR Inhibitors from TCM Database@Taiwan,” PLoS Computational Biology, vol. 7, no. 10, 2011.

[53] C.-Y. Chen and C. Y.-C. Chen, "Insights into designing the dual-targeted HER2/HSP90 inhibitors," Journal of Molecular Graphics and Modelling, vol. 29, no. 1, pp. 21-31, 2010.

[54] H.-J. Huang, K.-J. Lee, H. W. Yu et al., "Structure-based and ligand-based drug design for HER 2 receptor," Journal of Biomolecular Structure \& Dynamics, vol. 28, no. 1, pp. 23-37, 2010.

[55] W. Ieongtou, S. S. Chang, D. Wu et al., "Molecular level activation insights from a NR2A/NR2B agonist," Journal of Biomolecular Structure \& Dynamics, 2013.

[56] K.-C. Chen and C. Yu-Chian Chen, "Stroke prevention by traditional Chinese medicine? A genetic algorithm, support vector machine and molecular dynamics approach," Soft Matter, vol. 7, no. 8, pp. 4001-4008, 2011.

[57] K.-C. Chen, K.-W. Chang, H.-Y. Chen, and C. Y.-C. Chen, "Traditional Chinese medicine, a solution for reducing dual stroke risk factors at once?" Molecular BioSystems, vol. 7, no. 9, pp. 2711-2719, 2011.

[58] T.-T. Chang, K.-C. Chen, K.-W. Chang et al., "In silico pharmacology suggests ginger extracts may reduce stroke risks," Molecular BioSystems, vol. 7, no. 9, pp. 2702-2710, 2011.

[59] H. J. Huang, Y. R. Jian, and C. Y. Chen, "Traditional Chinese medicine application in HIV: an in silico study," Journal of Biomolecular Structure \& Dynamics, vol. 32, no. 1, pp. 1-12, 2014.

[60] C.-H. Lin, T.-T. Chang, M.-F. Sun et al., "Potent inhibitor design against $\mathrm{H} 1 \mathrm{N1}$ swine influenza: structure-based and molecular dynamics analysis for M2 inhibitors from traditional Chinese medicine database," Journal of Biomolecular Structure \& Dynamics, vol. 28, no. 4, pp. 471-482, 2011.

[61] T.-T. Chang, M.-F. Sun, H.-Y. Chen et al., "Screening from the world's largest TCM database against H1N1 virus," Journal of Biomolecular Structure \& Dynamics, vol. 28, no. 5, pp. 773-786, 2011.

[62] S.-S. Chang, H.-J. Huang, and C. Y.-C. Chen, "Two birds with one stone? Possible dual-targeting H1N1 inhibitors from traditional Chinese medicine," PLoS Computational Biology, vol. 7, no. 12, Article ID e1002315, 2011.

[63] C. Y. Chen, Y. H. Chang, D. T. Bau et al., "Ligand-based dual target drug design for H1N1: swine flu-a preliminary first study," Journal of Biomolecular Structure \& Dynamics, vol. 27, no. 2, pp. 171-178, 2009. 
[64] K. C. Chen, S. S. Chang, H. J. Huang et al., "Three-in-one agonists for PPAR-alpha, PPAR-gamma, and PPAR-delta from traditional Chinese medicine," Journal of Biomolecular Structure \& Dynamics, vol. 30, no. 6, pp. 662-683, 2012.

[65] P.-C. Chang, J.-D. Wang, M.-M. Lee et al., "Lose weight with traditional Chinese medicine? Potential suppression of fat mass and obesity-associated protein," Journal of Biomolecular Structure \& Dynamics, vol. 29, no. 3, pp. 471-483, 2011.

[66] H. J. Huang, K. J. Lee, H. W. Yu et al., "A novel strategy for designing the selective PPAR agonist by the "Sum of Activity" model," Journal of Biomolecular Structure \& Dynamics, vol. 28, no. 2, pp. 187-200, 2010.

[67] K. C. Chen, S. S. Chang, F. J. Tsai, and C. Y. Chen, "Han ethnicity-specific type 2 diabetic treatment from traditional Chinese medicine?" Journal of Biomolecular Structure \& Dynamics, vol. 31, no. 11, pp. 1219-1235, 2013.

[68] W. I. Tou, S. S. Chang, C. C. Lee, and C. Y. Chen, "Drug design for neuropathic pain regulation from traditional Chinese medicine," Scientific Reports, vol. 3, p. 844, 2013.

[69] K. C. Chen, Y. R. Jian, M. F. Sun et al., "Investigation of silent information regulator 1 (Sirt1) agonists from Traditional Chinese Medicine," Journal of Biomolecular Structure \& Dynamics, vol. 31, no. 11, pp. 1207-1218, 2013.

[70] V. Cody, J. R. Luft, and W. Pangborn, "Understanding the role of Leu22 variants in methotrexate resistance: comparison of wildtype and Leu22Arg variant mouse and human dihydrofolate reductase ternary crystal complexes with methotrexate and NADPH," Acta Crystallographica Section D: Biological Crystallography, vol. 61, no. 2, pp. 147-155, 2005.

[71] J. Phan, S. Koli, W. Minor, R. B. Dunlap, S. H. Berger, and L. Lebioda, "Human thymidylate synthase is in the closed conformation when complexed with dUMP and raltitrexed, an antifolate drug," Biochemistry, vol. 40, no. 7, pp. 1897-1902, 2001.

[72] Shanghai Innovative Research Center of Traditional Chinese Medicine (SIRC/TCM), S.I.R.C.o.T.C.M., Add:No.1 Building, 439 Chunxiao Road,Zhangjiang Hi-tech Park,Shanghai, 2012.

[73] C. Y.-C. Chen, “TCM Database@Taiwan: the world's largest traditional Chinese medicine database for drug screening In Silico," PLoS ONE, vol. 6, no. 1, Article ID e15939, 2011.

[74] X. Ma, G. Xiang, C.-W. Yap, and W.-K. Chui, "3D-QSAR Study on dihydro-1,3,5-triazines and their spiro derivatives as DHFR inhibitors by comparative molecular field analysis (CoMFA)," Bioorganic and Medicinal Chemistry Letters, vol. 22, no. 9, pp. 3194-3197, 2012.

[75] B. K. Slinker and S. A. Glantz, "Multiple linear regression: accounting for multiple simultaneous determinants of a continuous dependent variable," Circulation, vol. 117, no. 13, pp. 17321737, 2008.

[76] V. Vapnik, "Pattern recognition using generalized portrait method," Automation and Remote Control, vol. 24, pp. 774-780, 1963.

[77] O. Ivanciuc, "Applications of support vector machines in chemistry," Reviews in Computational Chemistry, vol. 23, pp. 291-400, 2007.

[78] V. Vapnik, The Nature of Statistical Learning Theory, Springer, 1995.

[79] C.-C. Chang and C.-J. Lin, "LIBSVM: a Library for support vector machines," ACM Transactions on Intelligent Systems and Technology, vol. 2, no. 3, article 27, 2011.

[80] R. Burbidge, M. Trotter, B. Buxton, and S. Holden, "Drug design by machine learning: support vector machines for pharmaceutical data analysis," Computers and Chemistry, vol. 26, no. 1, pp. 5-14, 2001.

[81] J. Yu, V. A. Smith, P. P. Wang, A. J. Hartemink, and E. D. Jarvis, "Advances to Bayesian network inference for generating causal networks from observational biological data," Bioinformatics, vol. 20, no. 18, pp. 3594-3603, 2004.

[82] N. Friedman, M. Linial, I. Nachman, and D. Pe'er, "Using Bayesian networks to analyze expression data," Journal of Computational Biology, vol. 7, no. 3-4, pp. 601-620, 2000. 


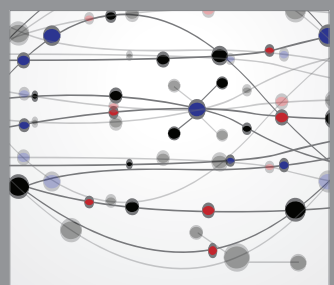

The Scientific World Journal
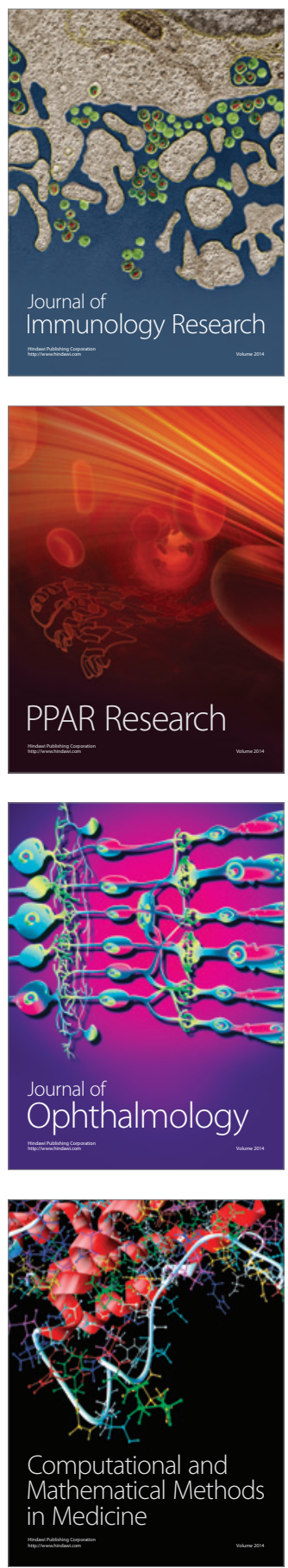

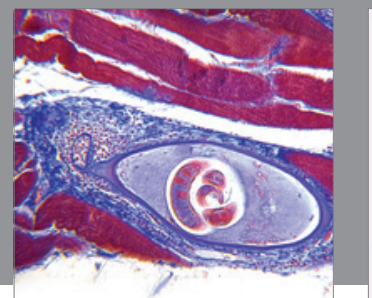

Gastroenterology

Research and Practice
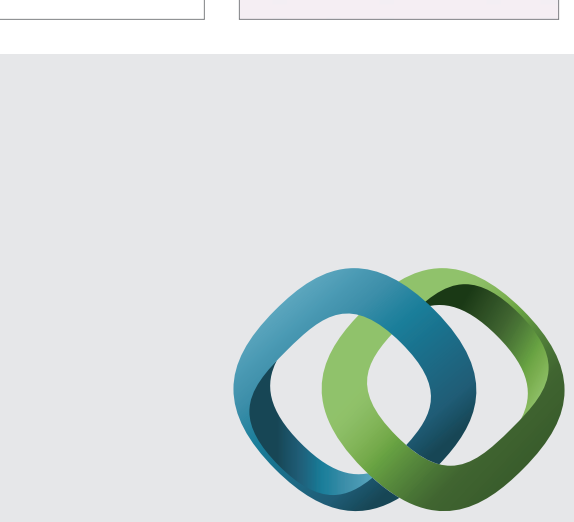

\section{Hindawi}

Submit your manuscripts at

http://www.hindawi.com
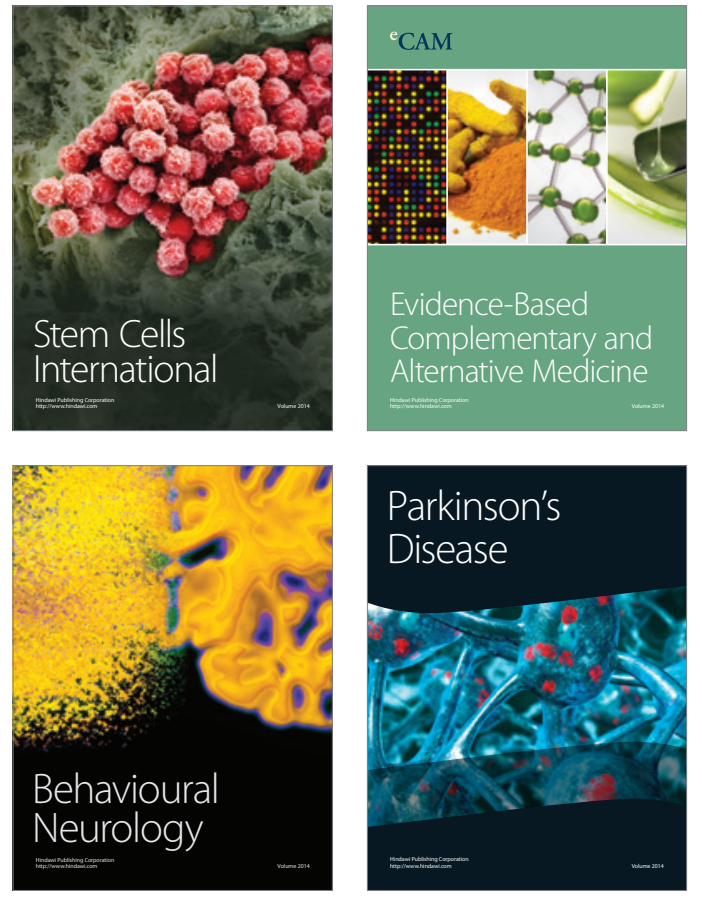
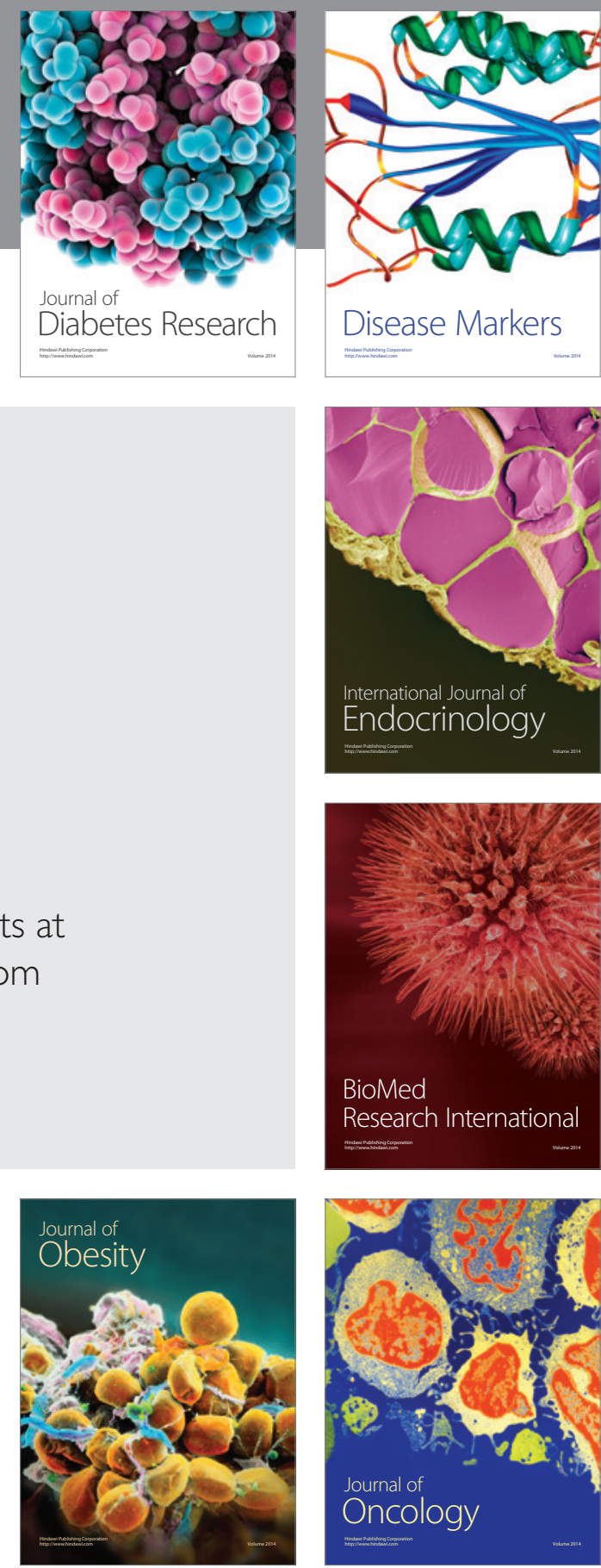

Disease Markers
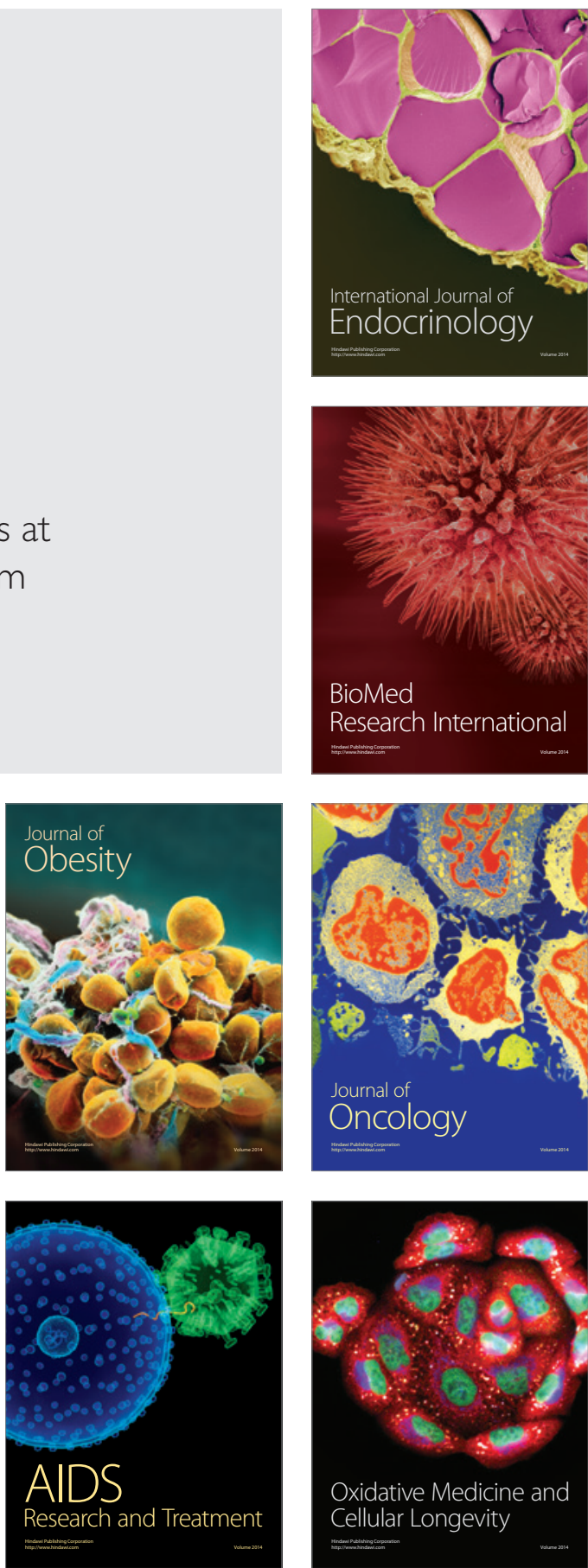